\title{
Differential Immune-Reactivity and Subcellular Distribution Reveal the Multifunctional Character of Profilin in Pollen as Major Effect of Sequences Polymorphism
}

\author{
Jose C. Jimenez-Lopez, Sonia Morales, Dieter Volkmann, \\ Juan D. Alché and María I. Rodriguez-Garcia
}

Additional information is available at the end of the chapter

http://dx.doi.org/10.5772/46170

\section{Introduction}

Profilin was first identified in plants as a birch allergen (Valenta et al. 1991). Plants have several genes encoding highly divergent profilin isoforms (Kovar et al. 2000; Kandasamy et al. 2002), differentially expressed, and with biochemical and functional diversity (Huang et al. 1996), particularly physiological roles in actin-based processes. Profilins are divided in two classes: one is ubiquitously present, and constitutively expressed in all plant tissues (vegetative), whereas the second class is restricted to the reproductive tissues (Kandasamy et al. 2002). At biochemical level, plant profilins are placed into two distinct classes: Class I profilins bind to phosphatidylinositol 4,5-bisphosphate [PtdIns $\left.(4,5) \mathrm{P}_{2}\right]$ much stronger than class II profilins, whereas class II have stronger affinity for actin and PLP (Gibbon et al 1998; Kovar et al 2000).

The complexity of profilin expression and the number of isoforms in higher plants is correlated with the observation that the actin family is also more complex in plants than in other kingdoms (McDowell et al. 1996). Structurally, Overall look to plant profilins indicates that they are similar to these from yeast and vertebrate, though the identity of primary amino acid sequence is only about 30\% (Fedorov et al. 1997; Thorn et al. 1997), which implicate profilins in key conserved functions throughout different kingdoms. However, the in vitro biochemical data suggested that different profilin isoform functions distinctly (Kovar et al. 2000), which supports an isovariant dynamics model where particular isoforms have differential functions/activities. Supporting this idea, it has been proposed that plant profilin family multi-functionality might be inferred by natural variation through profilin isovariants 
generated among germplasm, as a result of polymorphism. The high variability might result in both differential profilin properties and differences in the regulation of the interaction with natural partners, suggesting that isovariant dynamics may expand the responses of the actin cytoskeleton or buffer it to against stress (Jimenez-Lopez 2008, Jimenez-Lopez et al. 2012).

Profilin is a major regulator of actin dynamics and is crucial for cellular growth, morphogenesis and cytokinesis (Jockusch et al. 2007). In addition to binding to actin, profilins bind to other partners like stretch of poly-proline (PLP) and proline-rich proteins, and phospholipids. The proline-binding ability could be a major function, being different among profilin isoforms, affecting actin-based structures (Kovar et al. 2001). The importance of the binding of profilin to PLP is supported by the finding of the differential preference for profilin isoforms of formin (essential actin-binding and nucleator protein) (Neidt et al. 2009), together with the evidence that Arabidopsis formins have preference for different profilin isoforms (Deeks et al. 2005).

Another binding ligand of profilin is phospholipids. The binding of profilin to phospholipids links to its potential role in vesicle trafficking (Janssen and Schleicher 2001). Profilins have been revealed as key mediators of the membrane-cytoskeleton communication, acting at critical points of signaling pathways initiated by events in the plasma membrane and transmitted by transduction cascades to promote cytoskeletal rearrangements (Baluska et al. 2002). This functionality arises from their capacity of interaction with phosphatidylinositides (PIP2), as well as with poly-L-proline-rich proteins (Kovar et al. 2001).

Several locations have been attributed to profilin. They have been localized in different plant cells and tissues, including the microspores, pollen grains and pollen tubes (Grote et al. 1993, 1995; Hess et al. 1995; Fischer et al. 1996; Vidali \& Hepler 1997; Kandasamy 2002). Plant profilin was reported to be localized in the cytoplasm of pollen tube uniformly (Hess et al. 1995; Vidali \& Hepler 1997). However, no clear picture has yet been established about the precise location of profilin in the pollen tubes. In consideration of the existence of calcium gradient in pollen tube and the regulation of profilin's sequestering activity by calcium (Kovar et al. 2000), the existence of a gradient of total sequestering activity of profilin in the pollen tube is expected.

Upon pollen hydration and pollen germination, profilin was detected close to the site of pollen tube emergence, forming a ring-like structure around the apertural region. Profilin was also detected in the pollen exine of the germinating pollen grains and in the germination medium. Profilin was also localized in the cytoplasm of the pollen tube, particularly at both the proximal and apical ends (Morales et al. 2008).

Depending on the fixation and extraction protocol used, nuclear localization has been also observed (Buss et al. 1992). Profilin has also been found in generative and vegetative nuclei of Ledebouria socialis pollen (Hess and Valenta 1997), the nuclei of Phaseolus vulgaris cells (Vidali et al. 1995) and Arabidopsis thaliana and maize root hairs (Braun et al. 1999, Baluska et al. 2001). Microinjection of a fluorescently labeled birch profilin in Micrasterias denticulata also shows an accumulation of profilin in the nucleus (Holzinger et al. 1997). 
Other different profilin localizations have been described, like the chloroplast outer membrane, which interacts with CHUP1 protein during chloroplast movement in response to light (Schmidt von Braun and Schleiff 2008), and in amyloplasts (Fischer et al. 1996), in addition to a preferential localization in association with the plasma membrane. Moreover, a differential expression of different profilin isoforms has been reported in microspores and maize pollen (von Witsch et al. 1998). Profilin isoforms PRF1 and PRF2 were localized differentially in Arabidopsis epidermal cell (Wang et al. 2009), which emphasizes the existence of differentially regulated and localized profilin isoforms, as well as the necessity to determine the localization of each profilin isoform individually and carefully.

In the present study, we have used two experimental approaches: immune-reactivity in blotting experiments, and immunogold experiments for profilin cellular localization at TEM, with the aim of analyzing the differential immune-reactivity of profilins as result of their high sequence polymorphism, which also drives profilins the subcellular locations.

\section{Material and methods}

\subsection{Plant material}

Olive (Olea europaea L.) pollen was individually collected during May and June from olive trees of 24 cultivars, grown in the olive germplasm collection of the Estación Experimental del Zaidín, CSIC, Granada, Spain. Pollen samples were collected in large paper bags by vigorously shaking the inflorescences sequentially sieved through 150 and $50 \mu \mathrm{m}$ mesh filters to eliminate debris and maintained at $-80^{\circ} \mathrm{C}$.

Mature seeds from Acebuche (wild olive) and Picual cultivars were obtained from the same collection of well-characterized olive trees growing in the "Estación Experimental del Zaidín" (Granada, Spain), 210 days after anthesis (DAA).

\subsection{In vitro pollen germination}

Olive mature pollen from the Picual cultivar was in vitro germinated. Pre-hydration was performed by incubation in a humid chamber at $30^{\circ} \mathrm{C}$ for $30 \mathrm{~min}$. The grains $(0.02 \mathrm{~g} / \mathrm{plate})$ were then transferred to Petri dishes containing $10 \mathrm{~mL}$ of the germination medium $[10 \%$ $(\mathrm{w} / \mathrm{v})$ sucrose, $0.03 \%(\mathrm{w} / \mathrm{v}) \mathrm{Ca}\left(\mathrm{NO}_{3}\right)_{2}, 0.01 \%(\mathrm{w} / \mathrm{v}) \mathrm{KNO}_{3}, 0.02 \%(\mathrm{w} / \mathrm{v}) \mathrm{MgSO}_{4}$ and $0.03 \%$ $(\mathrm{w} / \mathrm{v})$ boric acid], as described by M'rani-Alaoui (2000). The Petri dishes were maintained at $25^{\circ} \mathrm{C}$ in the dark, and the pollen samples were taken at $5 \mathrm{~min}, 1,4,7$, and $18 \mathrm{~h}$ after the onset of the culture, pollen tube growth was monitoring by light microscopy. Finally, the pollen was pelleted by centrifugation $(1000 \times \mathrm{g}$ for $20 \mathrm{~s})$.

\subsection{Protein extraction}

Mature pollen or germinated samples were re-suspended in an extraction buffer (PBS), $\mathrm{pH}$ $7.4\left[140 \mathrm{mM} \mathrm{NaCl}, 2.7 \mathrm{mM} \mathrm{KCl}, 8.15 \mathrm{mM} \mathrm{Na}_{2} \mathrm{HPO}_{4}\right.$ and $1.8 \mathrm{mM} \mathrm{KH}_{2} \mathrm{PO}_{4}$ ] added with 10 
$\mu \mathrm{g} / \mu \mathrm{L}$ protease inhibitor cocktail (Sigma, Madrid, Spain) to a proportion of $5 \mathrm{~mL}$ solution per 0.5 gram of fresh tissue and then incubated at $4{ }^{\circ} \mathrm{C}$ for $4 \mathrm{~h}$ with vigorous shaking. After centrifugation at $13000 \times \mathrm{g}$ for $30 \mathrm{~min}$ at $4{ }^{\circ} \mathrm{C}$, the supernatants were removed, dispensed into aliquots and stored at $-20^{\circ} \mathrm{C}$. The process was repeated two times and proteins from both protein extractions were precipitated together overnight at $-20^{\circ} \mathrm{C}$ with a trichloroacetic acid solution.

$0.5 \mathrm{~g}$ of seeds material (cotyledons and endosperms) was directly homogenized to a very fine powder in a liquid nitrogen-precooled mortar with a pestle. $0.1 \mathrm{~g}$ of this powder was resuspended in $5 \mathrm{ml}$ of $1 \mathrm{M}$ Tris- $\mathrm{HCl}$ buffer, $\mathrm{pH} 7$ plus $0.7 \%$ sodium dodecyl sulfate (SDS) and 1\% 2-mercaptoethanol (denaturing, reducing conditions). After centrifugation at $10000 \mathrm{~g}$ for $15 \mathrm{~min}\left(4^{\circ} \mathrm{C}\right)$, the supernatants were filtered through $0.2 \mathrm{~mm}$ filter and stored at $-20{ }^{\circ} \mathrm{C}$.

The protein concentration was measured following the Bradford (1976) method, using the Bio-Rad reagent and bovine serum albumin (BSA) (Bio-Rad, Barcelona, Spain) as standard. In total, $30 \mu \mathrm{g}$ of protein per lane was loaded into a $12 \%$ sodium dodecyl sulfate (SDS)polyacrylamide gel (PAGE), as described by Laemmli (1970). The proteins were separated using a Mini-Protean system (Bio-Rad). After completion of SDS-PAGE, the gels were fixed and Coomassie blue stained [25\% methanol, 10\%acetic acid and 0.1\% Coomassie blue R250]. Digitized images were obtained using the Power Look III scanner and the MagicScan software (UMAX Systems GmbH, Germany).

\subsection{Protein transference and immunoblotting}

After completion of proteins separation by SDS-PAGE, they were transferred onto polyvinylidenedifluoride (PVDF) membranes at $25 \mathrm{~V}$ for $30 \mathrm{~min}$ in a semi-dry transfer cell (Bio-Rad) with transfer buffer containing $25 \mathrm{mM}$ Tris- $\mathrm{HCl} \mathrm{pH} 8.3,192 \mathrm{mM}$, and 20\% glycine. For immunodetection, blots were incubated for $4 \mathrm{~h}$ at $25{ }^{\circ} \mathrm{C}$ with a blocking solution containing $0.1 \%$ Tween 20 and $10 \%$ dried skimmed milk in Tris-buffered saline (TBS). The membranes were then probed with:

1. Whole olive and maize profilins polyclonal antibodies anti-ZmPRA (dilution 1:500) and anti-Ole e 2 (Morales et al. 2008) in a dilution 1:20000.

2. Polyclonal antibodies specific to particular isoforms of maize profilin like ZmPRO5 (Kovar et al. 2000), ZmPRO4 (Gibbon et al. 1998) and ZmPRO3 (Karakesisoglou et al. 1996), in a dilution 1:500.

An alkaline phosphatase-Conjugated anti-rabbit IgG (Promega Co) diluted 1:10000 served as the secondary antibody, and the detection reaction was developed using NBT-BCIP colorimetric system.

\subsection{Quantitations}

The intensity of each band was calculated from scanned images of gels by using the quantitation tools of the Quantity One v4.6.2 software (Bio-Rad Laboratories, USA). 


\subsection{Microscopy analysis}

\subsubsection{Immunolocalization of profilins in pollen by Transmission Electron Microscopy}

The germinated pollen grains were fixed for $2 \mathrm{~h}$ at $4{ }^{\circ} \mathrm{C}$ in $0.1 \%(\mathrm{v} / \mathrm{v})$ glutaraldehyde (GA) and $4 \%(\mathrm{w} / \mathrm{v})$ parformaldehyde $(\mathrm{PF})$ in buffer 1 . The samples were dehydrated in an ethanol series and embedded in Unicryl resin (BBInternational, Cardiff, UK) following a progressive lowering of temperature (PLT) schedule, as described by Alché et al. (1999). Ultra-thin sections $(80 \mathrm{~nm})$ were cut with an ultramicrotome (Reichert- Jung, Vienna, Austria) and transferred on to formvar-coated 300-mesh nickel grids. Blocking of non-specific binding sites was carried out by incubation of sections for $2 \mathrm{~h}$ in a solution containing $5 \%(w / v)$ BSA in washing buffer. The blocking was followed by washing in buffer 1 for $10 \mathrm{~min}$ and incubation at RT for $2.5 \mathrm{~h}$ with the antibodies described above, and their proper dilutions in the blocking solution. After washing several times with buffer 1, the grids were treated for 2 $\mathrm{h}$ with a goat anti-rabbit IgG secondary antibody coupled to 15 -nm gold particles (BBInternational) diluted 1/100 in the blocking solution. Finally, they were washed in buffer $1(5 \times 5 \mathrm{~min})$, rinsed in double-distilled water $(3 \times 5 \mathrm{~min})$ and then stained for $15 \mathrm{~min}$ with a solution of $5 \%(\mathrm{w} / \mathrm{v})$ uranyl acetate in the dark. The observations were carried out with a JEM-1011 (JEOL, Tokyo, Japan) TEM. The treatment of control sections was the same, although incubation with the primary antibody was omitted.

\subsection{Statistical analysis}

Statistical analysis was performed by using the SPSS v.18 statistical software package. A general comparison among multiple sample groups was performed throughout one-way analysis of variance (One-way ANOVA) on the basis of the Fisher-Snedecor distribution test $(\alpha=0.05$, significance value) (Mehta and Patel 1983). Normality and variances homogeneity of the data collection were checked by the Shapiro-Wilk test ( $\alpha=0.05$, significance value) (Shapiro and Wilk 1965) and the Levene test ( $\alpha=0.05$ significance value) (Levene 1960), respectively. Post hoc range probes and pair of species comparisons were carried out with the parametric test of Games-Howell ( $\alpha=0.05$, significance value) (Games and Howell 1976).

\section{Results}

\subsection{Expression and differential reactivity characterization of profilin from olive cultivars}

SDS-PAGE analysis of protein extracts of mature pollen from 24 olive cultivars showed distinctive protein profiles with different intensity.

$30 \mu \mathrm{g}$ of total protein was loaded in each line. The main protein bands of know pollen allergens correspond to the mayor olive pollen allergen Ole e 1, with a molecular weigh between 18-20 kDa. Defined protein bands corresponding to profilin around 13-15kDa are not clearly distinguishable (Figure 1). 


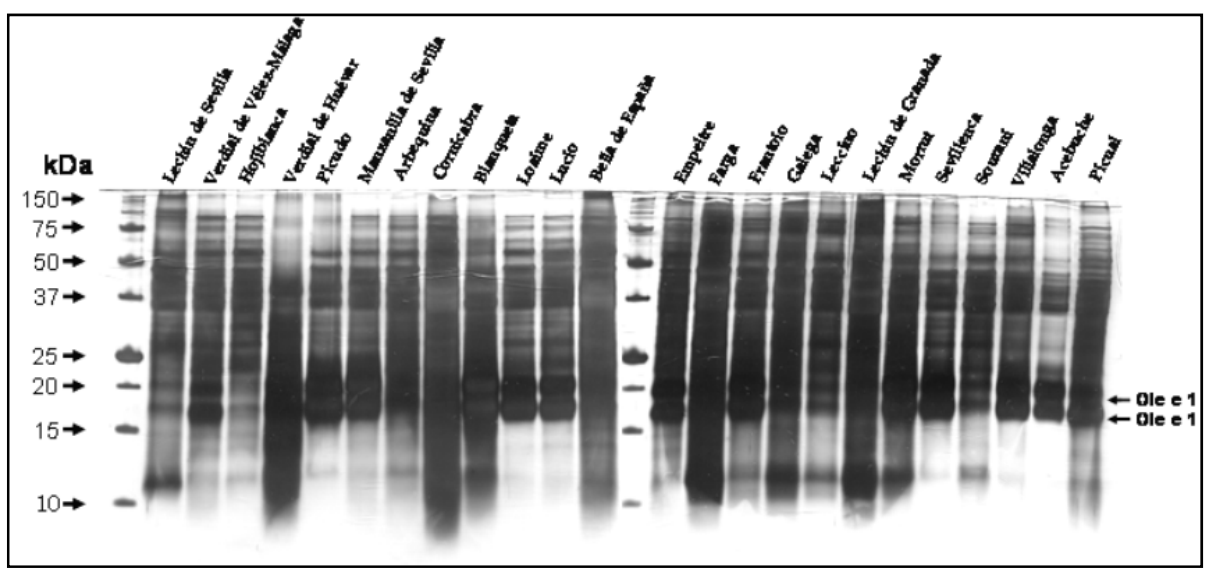

Figure 1. Protein profile of crude protein extract from 24 olive cultivars.

Cross-reactivity analysis between protein extracts from 24 olive cultivars with different antisera made against profilins from olive and maize pollen showed large differences both qualitative (intensity of bands) and quantitative (number of reactive bands) concerning profilins of MW around 13, 13.7 y 14.2kDa (Figure 2).

Statistical analysis of densitometric quantitations was performed. The variance analysis for the different antisera against different protein extracts from 24 olive cultivars (Figure 2 A to E) showed significant differences (F-ratio $=14.06, \mathrm{p}<0.05$ ). The reactivity values were inside a normal distribution (Shapiro-Wilk $=0.85, \mathrm{p}>0.05$ ), while the Levene test indicated non homogeneity of variances (Levene $=10.16, \mathrm{p}<0.05$ ).

Multiple comparisons of the five antisera by Games-Howell test determined the existence of statistically significant differences $(\mathrm{p}<0.05)$ between pairs of serum analyzed (anti-PRA to anti-ZmPRO4, anti-PRA to anti-ZmPRO3, anti-ZmPRO4 to anti-ZmPRO5, and antiZmPRO3 to anti-ZmPRO5, with Games-Howell test results of 73705.4, 70384.6, 124308.1 and 53923.4, respectively.

The analysis of the reactivity of the different cultivars against each individual antiserum showed statistical significant differences between Leccino and Picual, Lechín de Sevilla and Picudo, Lucio and Frantoio, Blanqueta and Farga, as well as between Picudo and Cornicabra corresponding to the immunoblots individually probed with anti-PRA, anti-ZmPRO3, antiZmPRO5, anti-ZmPRO4 y anti-Ole e 2, respectively (Figure 2A-E). Oppositely, it is possible to observe clear differences between antisera in their reactivity to defined cultivars, such as Hojiblanca, Arbequina, Cornicabra, Bella de España and Empeltre for the immunoblotting corresponding to anti-ZmPRO3; Lechin de Sevilla, Verdial de Huevar, Loaime, Lucio and Leccino for anti-ZmPRO4; and Sourani and Villalonga for anti-Ole e 2 (Figure 2A-E). 

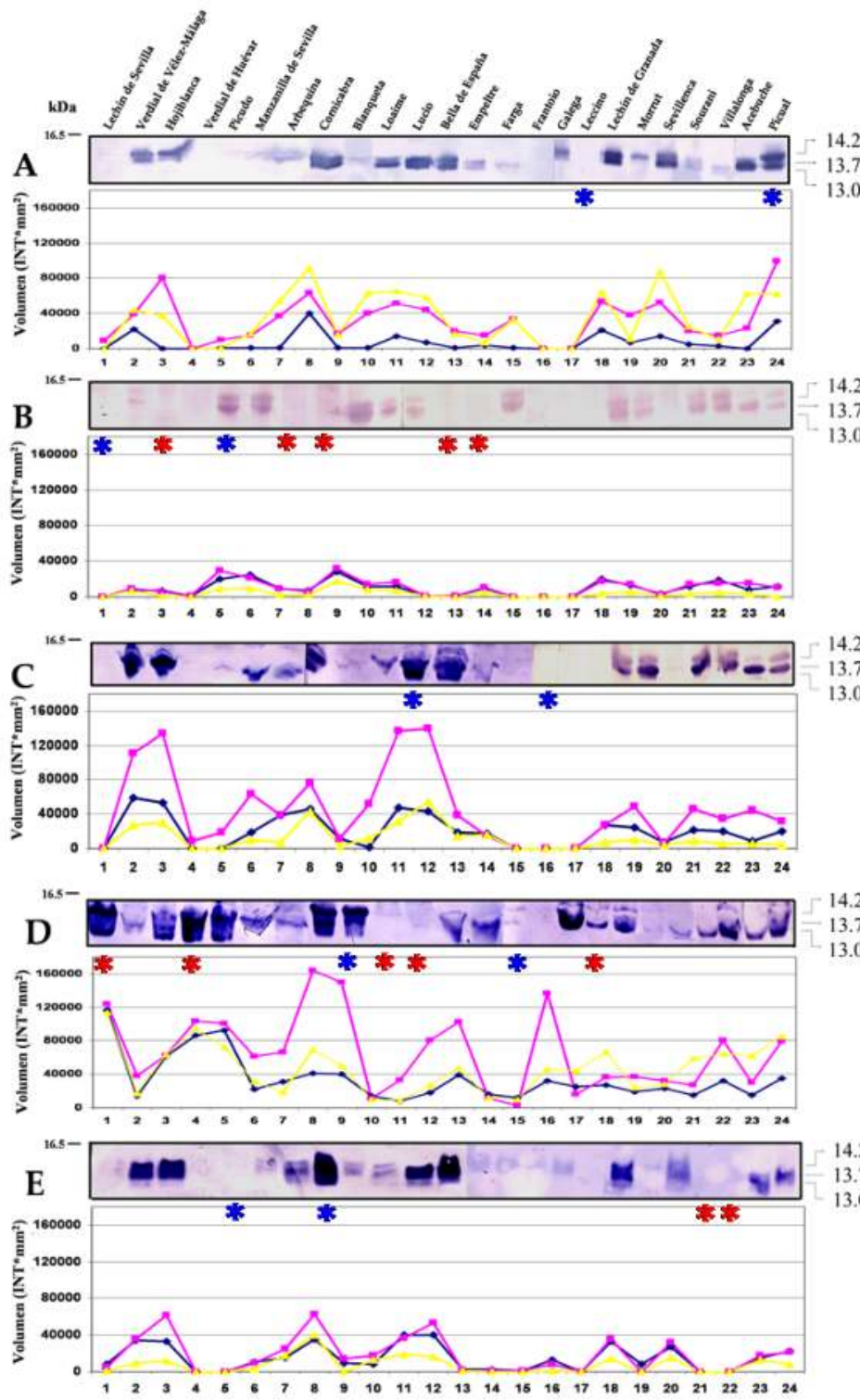

Figure 2. Immuno-reactivity analysis of profilin from 24 olive pollen cultivars. Reactivity of protein crude extracts from 24 olive cultivars was assayed against different maize profilin antisera, A) anti-PRA, B) anti-ZmPRO3, C) anti-ZmPRO5, D) anti-ZmPRO4, E) as well as against olive profilin antiserum antiOle e 2. Up to 3 reactive bands about $13,13.7$ and $14.2 \mathrm{kDa}$, corresponding to different isoforms of profilins were observed. The intensity of the reactive bands was quantitated by a densitometric analysis: yellow plot corresponding to $13 \mathrm{kDa}$ bands, pink (13.7 kDa) and blue (14.2 kDa). Red asterisks highlighted the differential reactivity (very high or very low) of defined cultivars to particular antisera, whereas blue asterisks highlighted the differential reactivity among cultivar to defined antisera. 


\subsection{Profilin expression and characterization of the differential reactivity of birch, hazel, timothy-grass and maize profilins}

SDS-PAGE analysis of protein extracts of mature pollen from Betula pendula, Corylus avellana, Phleum pratense and Zea mays displayed distinctive protein profiles in the figure 3. Defined protein bands corresponding to profilin are clearly distinguishable in the interval of 14$17 \mathrm{kDa}$, which is the expected size for profilin isoforms.

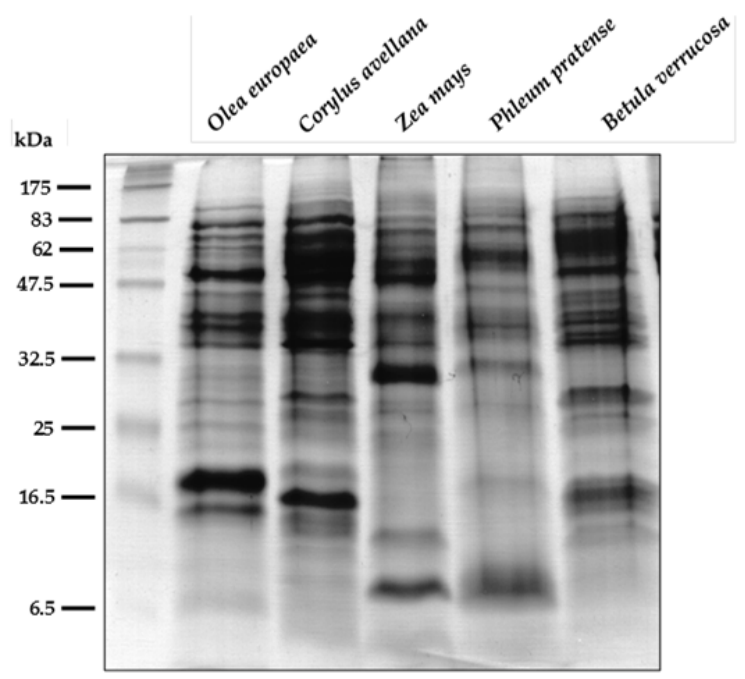

Figure 3. Protein profile of crude protein extract from pollen of 5 individual plant species. $30 \mu \mathrm{g}$ of total protein was loaded in each line.

Profilin immunodetection was performed by using the same antisera described above for olive. In this case, different antisera are able to distinguish up to two reactive bands, with molecular weights of 13.7 and $14.2 \mathrm{kDa}$ (Figure 4).

Clear differences can be appreciated when compared protein extracts reactivity of different species to individual antisera, as well as the reactivity of an individual protein extract to the different antisera assayed.

Cross-immune reactivity analysis between protein extracts from the five species with different antisera made against profilins from olive and maize pollen showed large differences both qualitative (intensity of bands) and quantitative (number of reactive bands) concerning profilins of MW around 13.7 and $14.2 \mathrm{kDa}$ (Figure 4).

Statistical analysis of densitometric quantitations was performed. The variance analysis for the different antisera against different protein extracts showed significant differences among the 5 species ( $\mathrm{F}-$ ratio $=8.13, \mathrm{p}<0.05)$.

The reactivity values were inside of a normal distribution (test de Shapiro-Wilk: 0.95, p>0.05), while the Levene test indicated non-homogeneity of variances (Levene: 2.86, $\mathrm{p}<0.05$ ). 


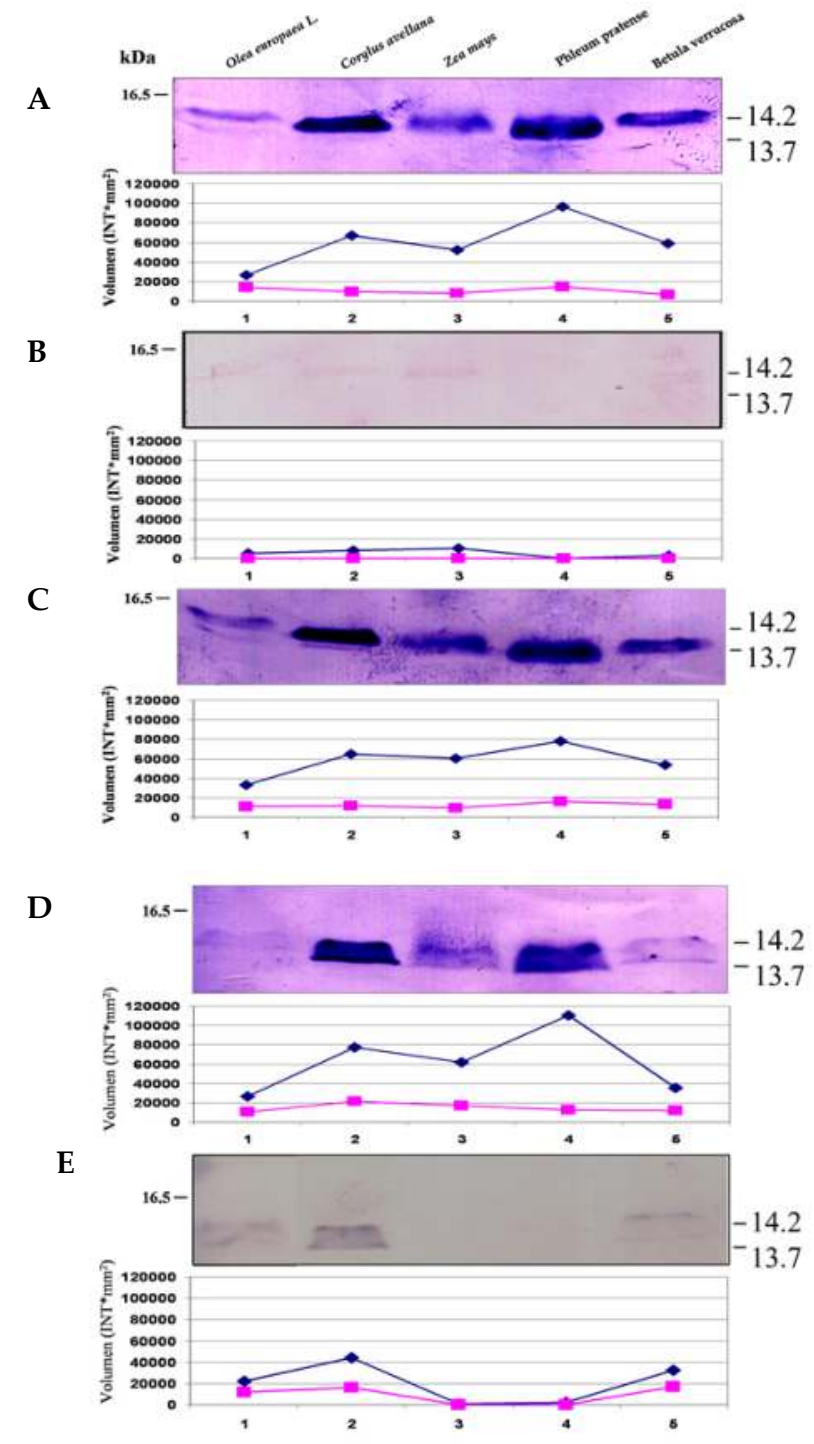

Figure 4. Immuno-reactivity analysis of crude protein extract from pollen of 5 plant species. Reactivity of proteins from 5 plant species were assayed against different maize profilin antisera, A) anti-PRA, B) anti-ZmPRO3, C) anti-ZmPRO5, D) anti-ZmPRO4, E) as well as against olive profilin antiserum anti-Ole e 2. It was appreciable up to 2 reactive bands about 13.7 and $14.2 \mathrm{kDa}$, corresponding to different isoforms of profilins for the species analyzed. The intensity of the reactive bands was quantitated by a densitometric analysis: pink color plot corresponded to 13.7kDa bands, and blue to $14.2 \mathrm{kDa}$. Red asterisks highlighted the differential reactivity (very high or very low) of defined species to different antisera, whereas blue asterisks highlighted the differential reactivity among cultivar to defined antiserum. 
Multiple comparison among the antisera showed statistically significant differences $(\mathrm{p}<0.05)$ between anti-ZmPRO3 and anti-PRA, anti-ZmPRO4, and anti-ZmPRO5, respectively, with Games-Howell test results of 65010.5, 64564.3 y 71150.2, respectively.

On the other hand, analysis of reactivity among species against individual antiserum showed statistical significant differences between Olea europaea L. and Phleum pratense, Olea europaea L. and Corylus avellana, Zea mays and Phleum pratense, and Corylus avellana and Zea mays for the antisera anti-PRA, anti-ZmPRO5, anti-ZmPRO4 and anti-Ole e 2, respectively.

Reversely, it is possible to observe clear differences between antisera for defined species, such as Corylus avellana and Phleum pratense for anti-ZmPRO3, and Phleum pratense for antiOle e 2 .

\subsection{Analysis of olive pollen profilin during in vitro germination}

The study of the olive pollen germination was aimed to analyze the differential expression of profilin isoforms during the germination process. Figure 5 showed the protein profiles of olive pollen extracts (cv. Picual) obtained after hydration, and at different times of germination (5 $\mathrm{min}, 1 \mathrm{~h}, 4 \mathrm{~h}, 7 \mathrm{~h}$ and $18 \mathrm{~h}$ ). No bands were distinguishable in the blue Coomassie blue stained gel around the molecular weight corresponding to profilins.

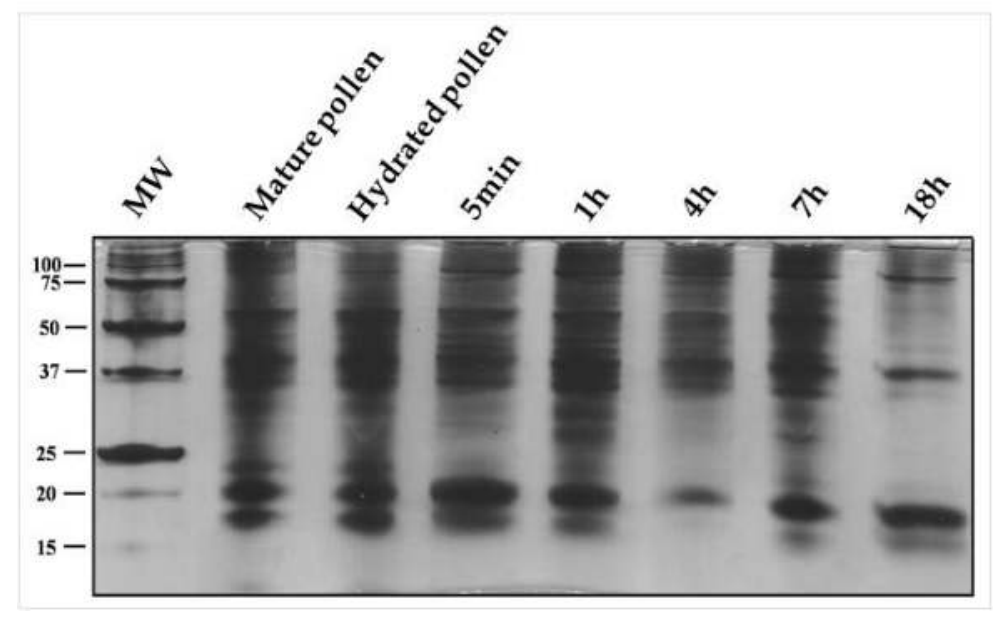

Figure 5. Protein profile of crude protein extract of mature olive pollen (cv. Picual) before and at different times of in vitro germination. $30 \mu \mathrm{g}$ of total protein was loaded in each line.

On the contrary, clear bands were obtained with immunoblotting experiments with the different antisera. 5 different bands can be distinguished corresponding to 5 different profilin isoforms (Figure 6), with calculated MW of 13.0, 13.7, 14.2, 14.9 and $15.7 \mathrm{kDa}$, respectively. 
A

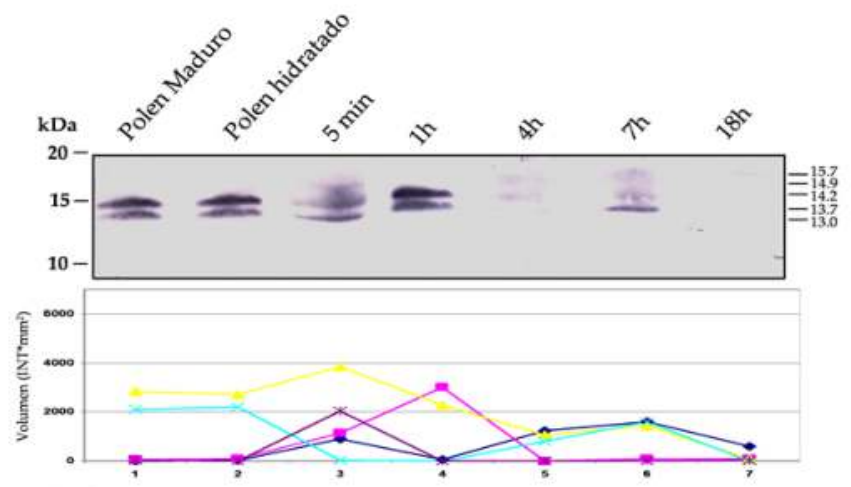

B
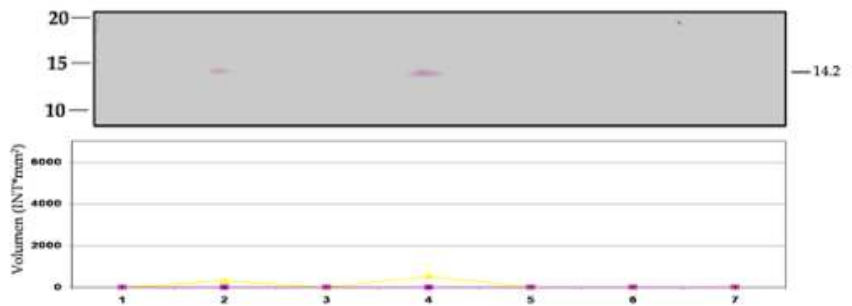

C

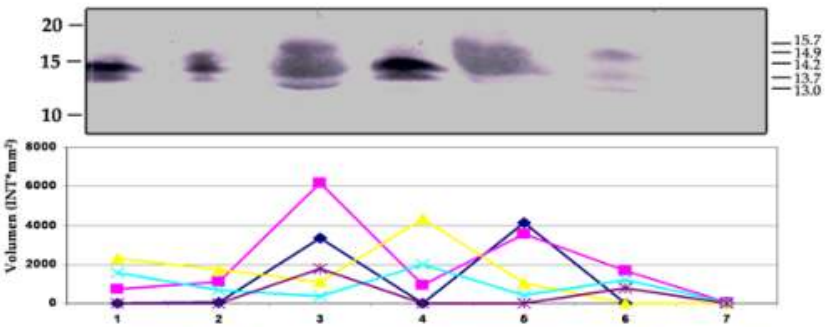

D
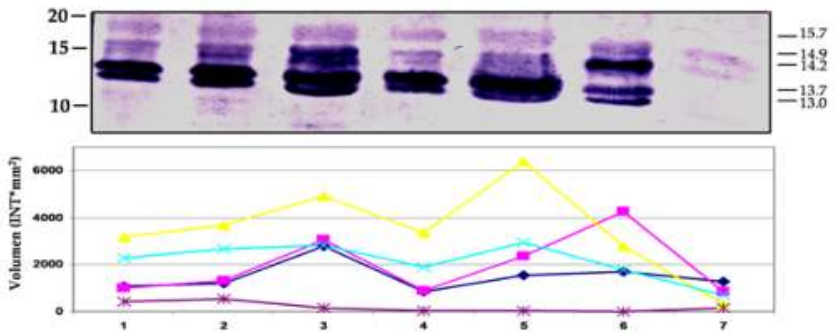

Figure 6. Immune-reactivity analysis of crude protein extract of mature olive pollen (cv. Picual) before and after in vitro germination. Reactivity of proteins extracts from mature pollen, as well as different stages of in vitro germination were assayed against different maize profilin antisera, a) anti-PRA, b) antiZmPRO3, c) anti-ZmPRO5, d) anti-ZmPRO4, e) as well as against olive profilin antiserum anti-Ole e 2. It was appreciable up to 5 reactive bands about 13.0, 13.7, 14.2, 14.9 y $15.7 \mathrm{kDa}$, corresponding to different isoforms of profilins. The intensity of the reactive bands was quantitated by a densitometric analysis: blue color plot corresponded to 13.0kDa bands, pink, yellow, turquoise, and brown color to 13.7, 14.2, 14.9 and $15.7 \mathrm{kDa}$, respectively. 
The expression pattern of profilin is similar during in vitro germination, although conspicuous differences of the antisera reactivity can be pointed out for the protein extracts. Level of protein isoforms expression in mature pollen and hydration stage were quite similar. On the other hand, there was a notable decrease of protein expression level, equally for all the isoforms at the end of germination (7-18 hours). Proteins expression level between $5 \mathrm{~min}$ and $4 \mathrm{~h}$ of germination was variable for the different profilin isoforms, particularly for the variants of 13.7 and $14.2 \mathrm{KDa}$.

\subsection{Analysis of cross-immunoreactivity between vegetative and reproductive profilins}

In order to determine the putative cross-reaction between reproductive profilins (see sections 3.1 to 3.3) and profilins from vegetative tissues, we have tested two of the antibodies used above (anti-ZmPRO4, and anti-ZmPRO5) against vegetative isoforms of maize profilins.

For this purpose, we have used protein extracts from olive seeds (cotyledon and endosperm) (cv Picual and Acebuche). The analysis of olive seed proteins Figure 7A showed a protein profile completely different to these of protein extracts from pollen. In this case, the mayor protein bands corresponded to different polypeptides of seed storage proteins, with MW ranging from 20 to $47 \mathrm{kDa}$ (Alché et al. 2006).
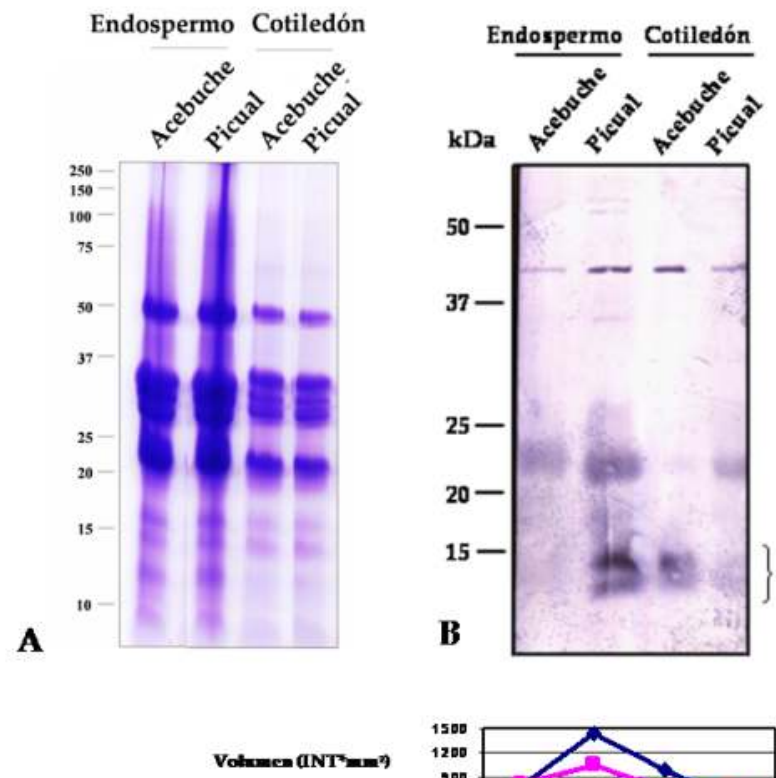

C

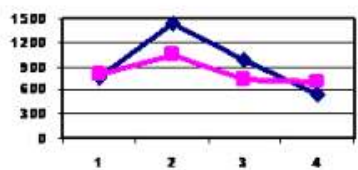

Figure 7. Immune-reactivity analysis of crude protein extract of vegetative profilins from olive seed tissues, cotyledon and endosperm. 
The immunoblotting analysis of seed proteins with anti-Ole e 2 showed at least two reactive bands located at 13.7 and $14.2 \mathrm{kDa}$ (Figure $7 \mathrm{~B}$ ). In addition, there were quantitative differences in the expression level of profilin concerning both tissues (cotyledon and endosperm) and cultivar. Thus, profilin in endosperm of cultivar Picual showed a higher level of immune-reactivity in comparison with profilins of cotyledon from the same cultivar.

Protein extracts from olive seed cultivars Acebuche and Picual were used in immunoblot experiments with antiserum anti-Ole e 2. A) SDS-PAGE of crude protein extract from olive seeds tissues (endosperm and cotyledon) of Acebuche and Picual cultivars. B) Inmunoblot of seeds protein samples from (A). Reactive bands were observed at 13.7 and $14.2 \mathrm{kDa}$, corresponding to vegetative profilins. C) Plot corresponding to the quantitation of reactive bands: blue lines were depicted for $14.2 \mathrm{kDa}$ bands, whereas pink color was used for 13.7 $\mathrm{kDa}$ reactive bands.

\begin{tabular}{|c|c|c|c|c|c|}
\hline Specie & $\begin{array}{c}\text { Sequence } \\
\text { GeneBank } \\
\text { Accession } N^{\circ}\end{array}$ & Chloroplast & Mitochondria & $\begin{array}{l}\text { Secretory } \\
\text { Pathway }\end{array}$ & $\begin{array}{c}\text { Others (Cytoplasm, } \\
\text { Microsomes) }\end{array}$ \\
\hline \multirow{15}{*}{$\begin{array}{c}\text { Olea } \\
\text { europaea L. }\end{array}$} & - & $13.2 \pm 1.6$ & $8.2 \pm 0.8$ & $9.8 \pm 0.5$ & $68.8 \pm 0.7$ \\
\hline & DQ640909 & $5.9 \pm 0.0$ & $4.4 \pm 0.0$ & $39.9 \pm 0.0$ & $49.8 \pm 0.0$ \\
\hline & DQ640910 & $7.6 \pm 0.0$ & $7.0 \pm 0.0$ & $20.0 \pm 0.0$ & $65.4 \pm 0.0$ \\
\hline & DQ640906 & $5.8 \pm 0.0$ & $5.3 \pm 0.0$ & $32.2 \pm 0.0$ & $56.7 \pm 0.0$ \\
\hline & DQ640903 & $9.7 \pm 0.0$ & $7.4 \pm 0.0$ & $14.2 \pm 0.0$ & $68.7 \pm 0.0$ \\
\hline & DQ640908 & $7.9 \pm 0.0$ & $7.8 \pm 0.0$ & $17.0 \pm 0.0$ & $67.3 \pm 0.0$ \\
\hline & DQ317580 & $6.7 \pm 0.0$ & $4.8 \pm 0.0$ & $28.4 \pm 0.0$ & $60.1 \pm 0.0$ \\
\hline & DQ640904 & $8.2 \pm 0.0$ & $6.8 \pm 0.0$ & $15.2 \pm 0.0$ & $69.8 \pm 0.0$ \\
\hline & DQ663553 & $6.7 \pm 0.0$ & $4.8 \pm 0.0$ & $28.4 \pm 0.0$ & $60.1 \pm 0.0$ \\
\hline & DQ663554 & $6.7 \pm 0.0$ & $4.8 \pm 0.0$ & $28.5 \pm 0.0$ & $60.0 \pm 0.0$ \\
\hline & DQ663555 & $6.9 \pm 0.0$ & $4.4 \pm 0.0$ & $28.2 \pm 0.0$ & $60.5 \pm 0.0$ \\
\hline & DQ663556 & $6.7 \pm 0.0$ & $4.8 \pm 0.0$ & $28.5 \pm 0.0$ & $60.0 \pm 0.0$ \\
\hline & DQ663558 & $8.7 \pm 0.0$ & $6.8 \pm 0.0$ & $20.0 \pm 0.0$ & $64.5 \pm 0.0$ \\
\hline & DQ640905 & $7.1 \pm 0.0$ & $8.4 \pm 0.0$ & $16.5 \pm 0.0$ & $68.0 \pm 0.0$ \\
\hline & DQ60907 & $8.2 \pm 0.0$ & $6.8 \pm 0.0$ & $15.3 \pm 0.0$ & $69.7 \pm 0.0$ \\
\hline $\begin{array}{c}\text { Betula } \\
\text { pendula }\end{array}$ & - & $14.4 \pm 1.1$ & $8.6 \pm 0.5$ & $11.7 \pm 0.3$ & $65.3 \pm 1.0$ \\
\hline \multirow{3}{*}{$\begin{array}{l}\text { Corylus } \\
\text { avellana }\end{array}$} & - & $14.4 \pm 0.1$ & $8.1 \pm 0.1$ & $13.2 \pm 0.5$ & $64.6 \pm 0.4$ \\
\hline & DQ663545 & $8.4 \pm 0.0$ & $6.8 \pm 0.0$ & $22.3 \pm 0.0$ & $62.5 \pm 0.0$ \\
\hline & DQ663547 & $6.5 \pm 0.0$ & $4.2 \pm 0.0$ & $27.7 \pm 0.0$ & $61.6 \pm 0.0$ \\
\hline $\begin{array}{l}\text { Phleum } \\
\text { pratense }\end{array}$ & - & $6.6 \pm 0.2$ & $5.0 \pm 0.3$ & $27.9 \pm 0.7$ & $61.5 \pm 1.4$ \\
\hline \multirow{2}{*}{ Zea mays } & - & $7.8 \pm 0.1$ & $7.2 \pm 0.1$ & $19.7 \pm 0.4$ & $65.4 \pm 0.4$ \\
\hline & X73280 & $2.5 \pm 0.0$ & $9.9 \pm 0.0$ & $27.1 \pm 0.0$ & $60.5 \pm 0.0$ \\
\hline
\end{tabular}

Table 1. Score calculated for the probability of finding a specific profilin in a particular cellular location. Bold numbers indicate that the score calculated for these sequences markedly differed from the average value. 


\subsection{Cellular localization of profilin}

\subsubsection{Predicting the cellular localization of profilin}

Predictions of the cellular location for profilins were carried out based in their primary sequence, and the putative presence of signal peptides responsible for targeting these proteins to specific cellular locations.

Probability of profilins location was calculated by using the tools TargetP (www.cbs.dtu.dk) and v2.0 PSORT (psort.hgc.jp). Table 1 shows the average values of probability for profilins location in different cellular compartments.

Overall, profilins exhibited high probability for cytoplasm localization. However, some sequences had a significant score for being localized in mitochondria and chloroplasts, while others were targeted to the secretory pathway. These data were confirmed by the program SignalP 3.0 Server (www.cbs.dtu.dk) (results not shown).

In addition, it was calculated the average probability of nuclear localization of profilins in the table 2, where different sequences from species exhibited a higher or lower probability of localization in comparison with an average score. Based in the average score, profilins from Olea europaea L. are most likely localized in nucleus compared with the other species.

Plant profilins analyzed have a targeting motif for nuclear localization which sequence is (RGKKGXGG(I/V)T(I/V)KKT) (Yoneda 1997).

\begin{tabular}{|c|c|c|}
\hline Specie & $\begin{array}{c}\text { Sequence GenBank } \\
\text { Accession } \mathbf{N}^{\circ}\end{array}$ & $\begin{array}{c}\text { Probability of Nuclear } \\
\text { Location }(\%)\end{array}$ \\
\hline \multirow{4}{*}{ Olea europaea L. } & - & $34.8 \pm 3.3$ \\
\hline & DQ138337 & $19.0 \pm 0.1$ \\
\hline & DQ138325 & $18.0 \pm 0.1$ \\
\hline & DQ117904 & $19.0 \pm 0.1$ \\
\hline Betula pendula & - & $25.5 \pm 0.7$ \\
\hline \multirow{2}{*}{ Corylus avellana } & - & $29.1 \pm 0.8$ \\
\hline & DQ663545 & $17.0 \pm 0.1$ \\
\hline \multirow{5}{*}{ Phleum pratense } & - & $27.8 \pm 1.5$ \\
\hline & X77583 & $33.0 \pm 0.1$ \\
\hline & Y09546 & $32.0 \pm 0.1$ \\
\hline & Y09457 & $31.0 \pm 0.1$ \\
\hline & Y09458 & $32.0 \pm 0.1$ \\
\hline \multirow{3}{*}{ Zea mays } & - & $26.9 \pm 2.0$ \\
\hline & X73279 & $32.0 \pm 0.1$ \\
\hline & X73280 & $35.0 \pm 0.1$ \\
\hline
\end{tabular}

Table 2. Score of probability for nuclear distribution of profilins. Bold numbers indicate the average probability.

The polymorphism of the profilin sequences concerning this motif is depicted in the table 3 . Overall, micro-heterogeneities in this motif were identified for several sequences of olive, 
hazel and timothy-grass. These changes can represent differences in the affinity for localization of particular profilin isoforms in defined cellular locations.

\begin{tabular}{|c|c|c|c|c|c|}
\hline Specie & $\begin{array}{c}\text { Sequence } \\
\text { GeneBank } \\
\text { Accession N }{ }^{\circ}\end{array}$ & $\begin{array}{c}\text { Nuclear Targeting } \\
\text { Motif }\end{array}$ & Specie & $\begin{array}{c}\text { Sequence } \\
\text { GeneBank } \\
\text { Accession N }{ }^{\circ} \\
\end{array}$ & $\begin{array}{c}\text { Nuclear Targeting } \\
\text { Motif }\end{array}$ \\
\hline \multirow{15}{*}{$\begin{array}{c}\text { Olea } \\
\text { europaea } \\
\text { L. }\end{array}$} & DQ640909 & RGKKGAGGITIKKT & \multirow{2}{*}{$\begin{array}{l}\text { Corylus } \\
\text { avellana }\end{array}$} & DQ663545 & RGKKGAGGITVKKT \\
\hline & DQ640910 & RGKKGAGGITVKKT & & DQ663547 & RGKKGAGGITVKKT \\
\hline & DQ138336 & RGKKGAGGITIKKT & \multirow{12}{*}{$\begin{array}{l}\text { Phleum } \\
\text { pratense }\end{array}$} & X77583 & RGKKGAGGITIKKT \\
\hline & DQ640906 & RGKKGAGGITIKKT & & Y09546 & RGKKGAGGITIKKT \\
\hline & DQ640908 & RGKKGAGGITVKKT & & Y09457 & RGKKGAGGITIKKT \\
\hline & DQ317574 & RGKKGSGGITSKKT & & Y09458 & RGKKGAGGITIKKT \\
\hline & DQ663553 & RGKKGAGGITIKKT & & DQ663535 & RGKKGAGGITIKKT \\
\hline & DQ663554 & RGKKGAGGITIKKT & & DQ663536 & RGKKGAGGITIKKT \\
\hline & DQ663555 & RGKKGAGGITIKKT & & DQ663537 & RGKKGAGGITIKKT \\
\hline & DQ663556 & RGKKGAGGITIKKT & & DQ663538 & RGKKGAGGITIKKT \\
\hline & DQ663557 & RGKKGAGGITIKKT & & DQ663539 & RGKKGAGGITIKKT \\
\hline & DQ640905 & RGKKGAGGITVKKT & & DQ663540 & RGKKGAGGITIKKT \\
\hline & DQ138358 & RGKKGTGGITIKKT & & DQ663541 & RGKKGAGGITIKKT \\
\hline & DQ138352 & RGKKGSGGITIKET & & DQ663542 & RGKKGAGGITIKKT \\
\hline & DQ138354 & RGKKGSGGITIKET & & & \\
\hline
\end{tabular}

Table 3. Changes in the motif targeting to a nuclear localization of profilin sequences.

Sequence of nuclear motif is characterized by the sequence RGKKGXGG(I/V)T(I/V)KKT, where $X$ is the amino acid serine (S) in the majority of the analyzed sequences. The variable amino acids were highlighted in bold and red color.

\subsubsection{Experimental approach for profilin cellular localization}

The experimental approach for profilin localization was performed to determine whether there is really a differential distribution of profilin isoforms. Immuno-localization assays were performed by transmission electron microscopy (TEM) in ultrathin sections of germinated pollen grains of olive (cv. Picual) using different antisera: anti-Ole e 2 and antiPRA (Figures 8 and 9), anti-ZmPRO3 (Figure 10), anti-ZmPRO4 (Figure 11), anti-ZmPRO5 (Figure 12).

All immune-localizations showed that profilins (gold particles) were preferentially located in the cytoplasm (Figures 8A and 9-12A), in addition to both nuclei of vegetative/generative cell (Figures 8A and 9A). Moreover, abundant gold grains were located in the pollen apertures (Figures 8C, 10C and 11C), in along the pollen wall, pollen tube and the pollen tip (Figures 8A and 9-12B), as well as in the material associated with the pollen grain exine (pollen coat) (Figures 8B, 11B and 12C). No significant number of labeling were found in the negative controls, for which were omitted the primary antiserum (Figure 9C). The overall number of gold grains in the sections was variable, and depending on the antiserum used. 


\begin{tabular}{cccccc}
\hline \multicolumn{7}{c}{ Profilin distribution } & & \\
\hline Antiserum & Cytoplasm & $\begin{array}{c}\text { Pollen } \\
\text { Coat }\end{array}$ & Aperture & $\begin{array}{c}\text { Negative } \\
\text { Control }\end{array}$ & $\begin{array}{c}\text { Pollen } \\
\text { Germination } \\
\text { Media }\end{array}$ \\
\hline Anti-PRA & $6.06 \pm 3.94$ & $7.83 \pm 4.67$ & $8.22 \pm 2.22$ & $2.00 \pm 0.42$ & $27.13 \pm 8.89$ \\
\hline Anti-ZmPRO3 & $34.70 \pm 9.66$ & $8.83 \pm 4.54$ & $4.86 \pm 2.04$ & $5.00 \pm 0.87$ & $48.56 \pm 23.76$ \\
\hline Anti-ZmPRO4 & $5.91 \pm 3.02$ & $4.34 \pm 1.32$ & $10.83 \pm 3.06$ & $2.00 \pm 0.38$ & $32.75 \pm 9.63$ \\
\hline Anti-ZmPRO5 & $13.00 \pm 3.35$ & $5.14 \pm 1.95$ & $2.20 \pm 0.45$ & $3.00 \pm 0.44$ & $18.70 \pm 17.36$ \\
\hline
\end{tabular}

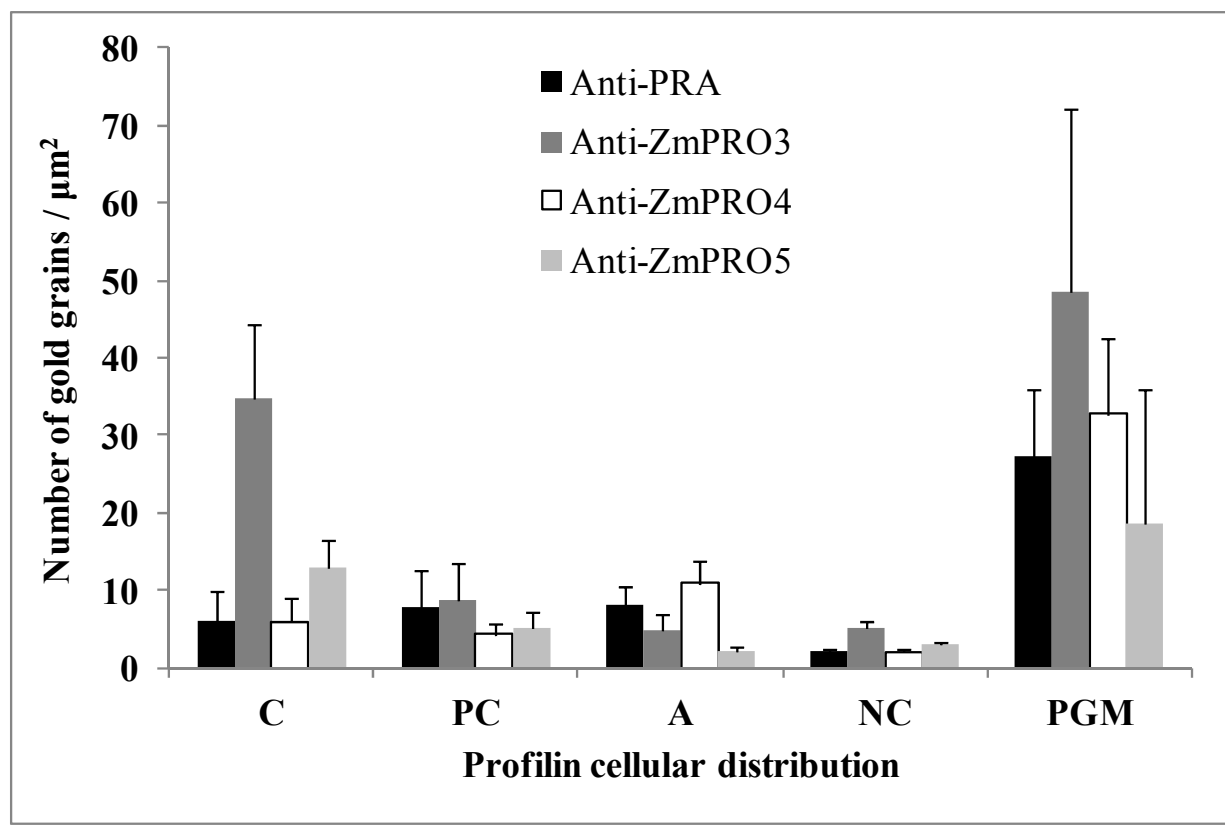

Table 4. Gold grains count for each antiserum used in this study. Measures corresponded to gold grains $/ \mu \mathrm{m}^{2}$. Profilin counting values corresponding to the different subcellular localization were

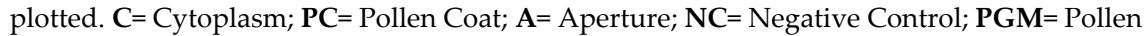
Germination Media.

In order to determine differences in the gold grain distribution for the different antisera used as markers for profilin isoforms, we proceeded to count the gold particles present on each of the above mentioned compartments. The results of this quantitation are showed in the table 4. The most abundant immunolabeling was observed in sections incubated with individual antiserum following the next order: anti-ZmPRO3 $>\mathrm{ZmPRO} 4>\mathrm{ZmPRO}$. Antisera anti-ZmPRO5 and $\mathrm{ZmPRO} 3$ showed a preferential cytoplasmic immunolocalization, whereas anti-PRA and anti-ZmPRO4 showed a preferential localization in the apertural regions of the pollen grain. 


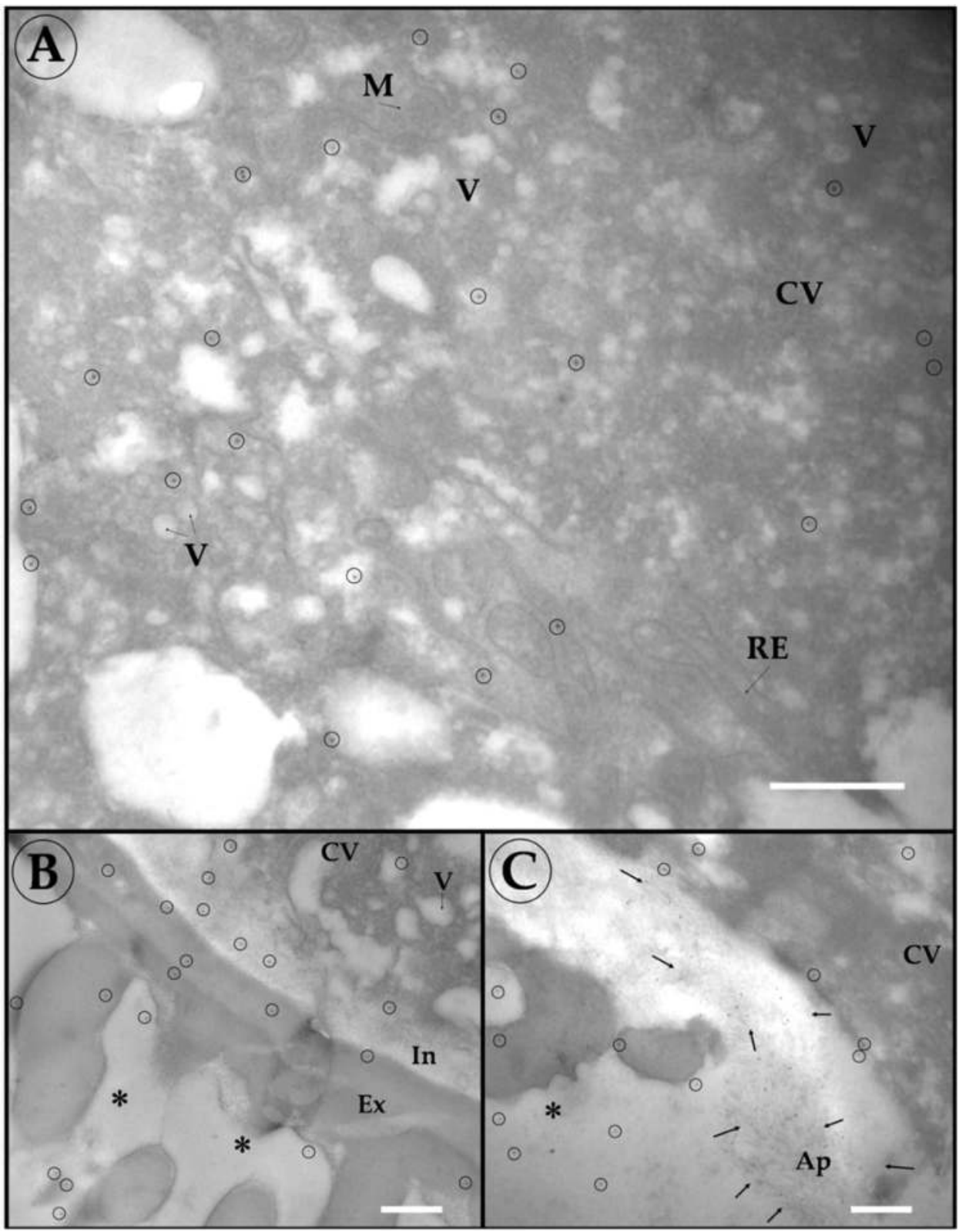

Figure 8. TEM immune-localization of olive pollen profilin in sections of mature pollen (cv Picual) during in vitro germination by using anti-Ole e 2 antiserum. A) General view of the vegetative cell cytoplasm, B) pollen grain walls C) and the apertural region. The location of the gold particles is highlighted with circles and arrows. Ap: apertures; CV: vegetative cell cytoplasm, Ex: exine, In: intine, M: mitochondria, N: nucleus, P: plastid, ER: endoplasmic reticulum; V: vesicle, asterisks: material adhered to the pollen walls (pollen coat). The bars represent $1 \mu \mathrm{m}$. 


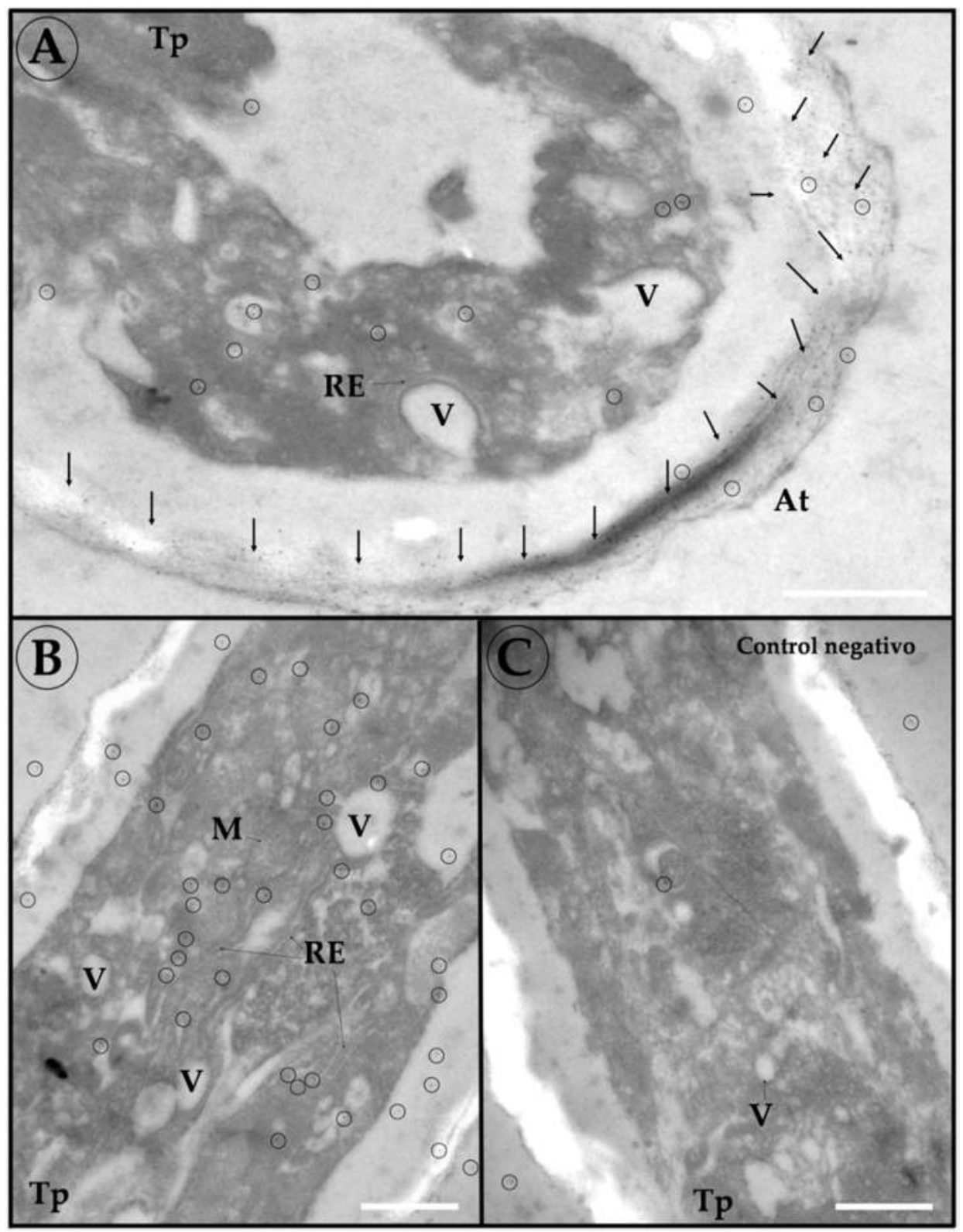

Figure 9. TEM immune-localization of olive pollen profilin in sections of mature pollen (cv Picual) during in vitro germination by using anti-PRA antiserum. A) General view of the pollen tip, B) longitudinal section of a pollen tube, and C) negative control. The location of the gold particles is highlighted with circles and arrows. Ap: apertures; CV: vegetative cell cytoplasm, Ex: exine, In: intine, M: mitochondria, N: nucleus, P: plastid, ER: endoplasmic reticulum; Tp: pollen tube; V: vesicle, asterisks: pollen coat. The bars represent $1 \mu \mathrm{m}$. 


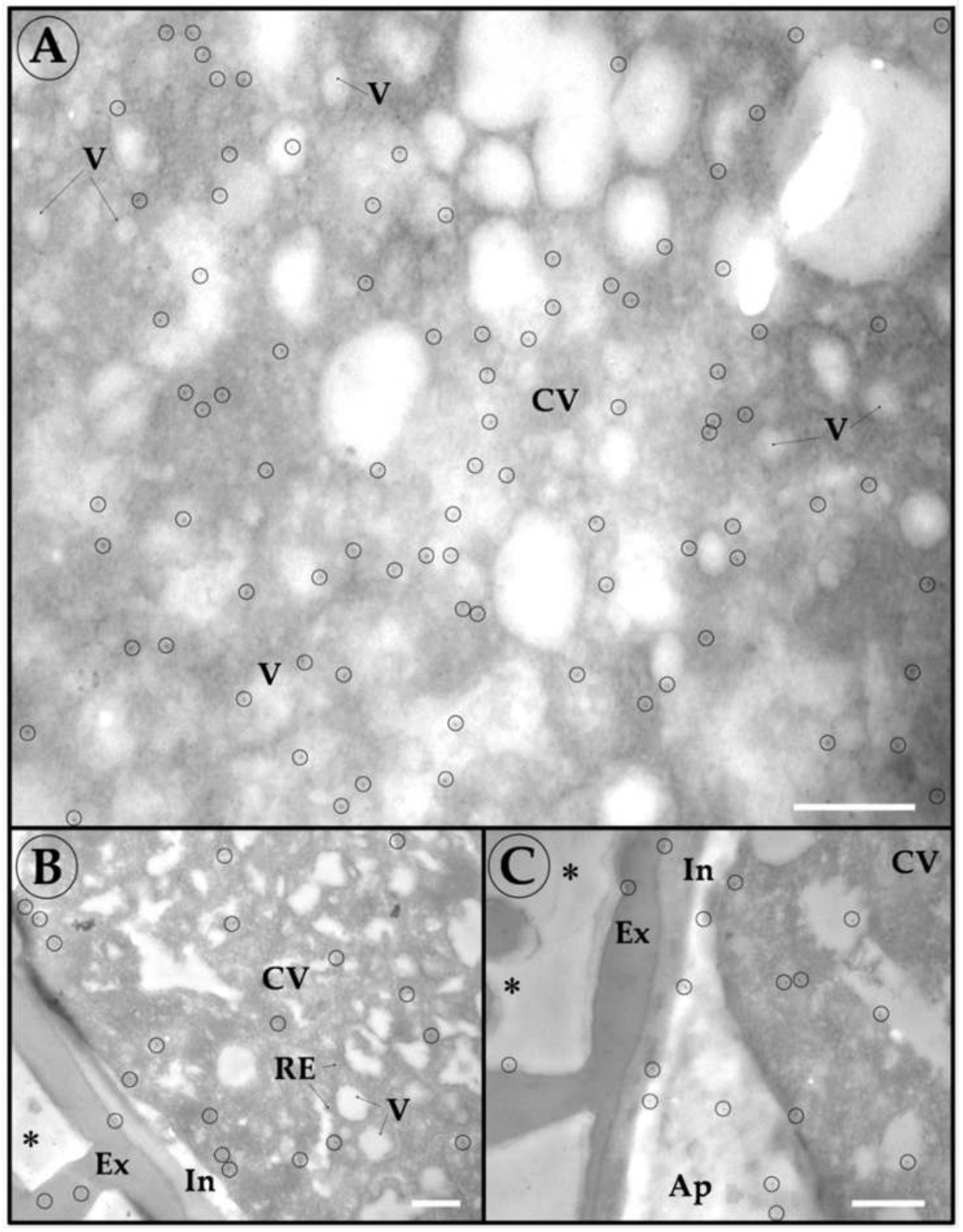

Figure 10. TEM immune-localization of olive pollen profilin in sections of mature pollen (cv Picual) during in vitro germination by using anti-ZmPRO3 antiserum. A) General view of the vegetative cell cytoplasm, B) pollen grain walls, and C) apertural region. The location of the gold particles is highlighted with circles and arrows. Ap: apertures; CV: vegetative cell cytoplasm, Ex: exine, In: intine, M: mitochondria, N: nucleus, P: plastid, ER: endoplasmic reticulum; V: vesicle, asterisks: pollen coat. The bars represent $1 \mu \mathrm{m}$. 


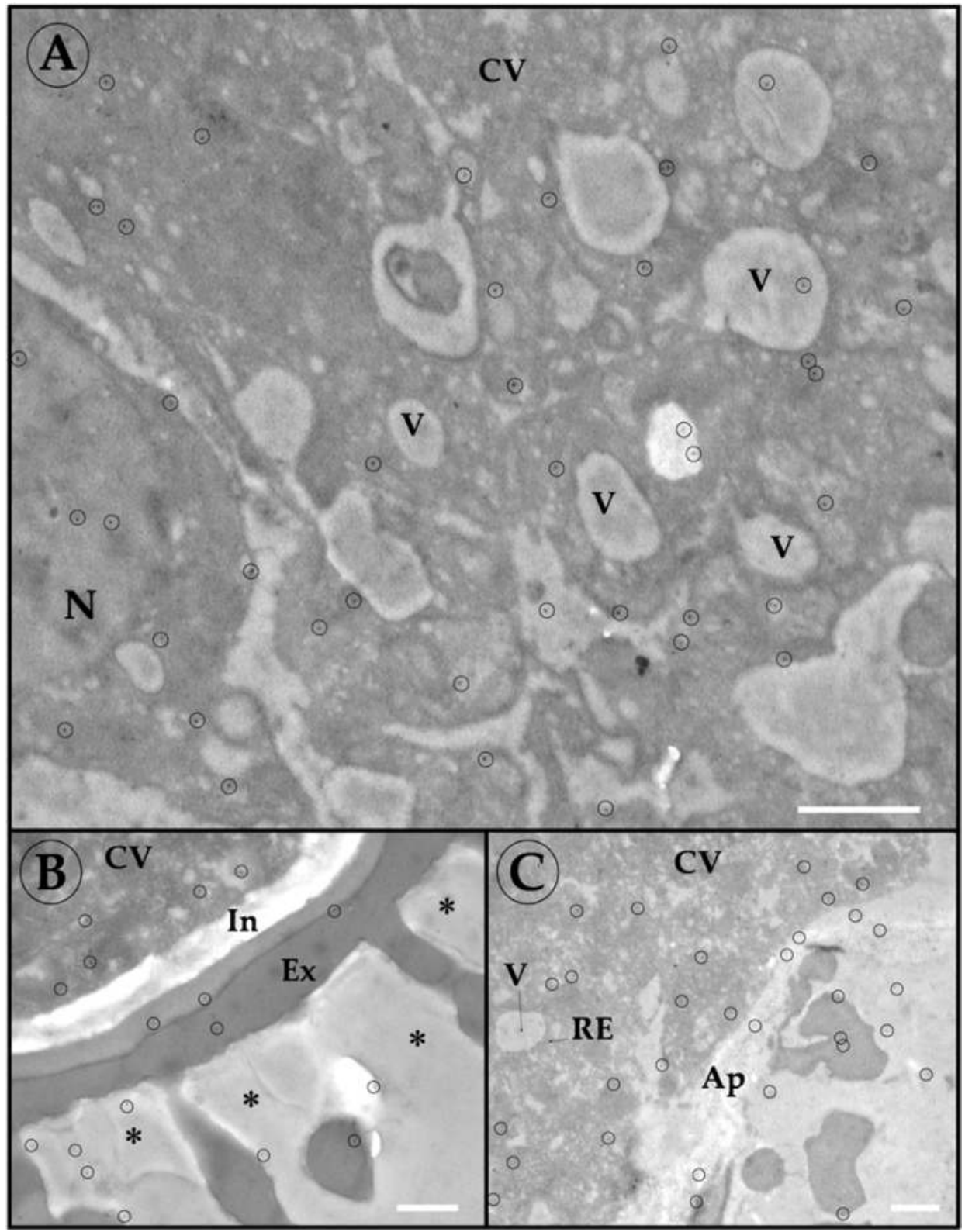

Figure 11. TEM immune-localization of olive pollen profilin in sections of mature pollen (cv Picual) during in vitro germination by using anti-ZmPRO4 antiserum. A) General view of the vegetative cell cytoplasm, B) pollen grain walls, and C) apertural region. The location of the gold particles is highlighted with circles and arrows. Ap: apertures; CV: vegetative cell cytoplasm, Ex: exine, In: intine, M: mitochondria, N: nucleus, P: plastid, ER: endoplasmic reticulum; V: vesicle, asterisks: pollen coat. The bars represent $1 \mu \mathrm{m}$. 


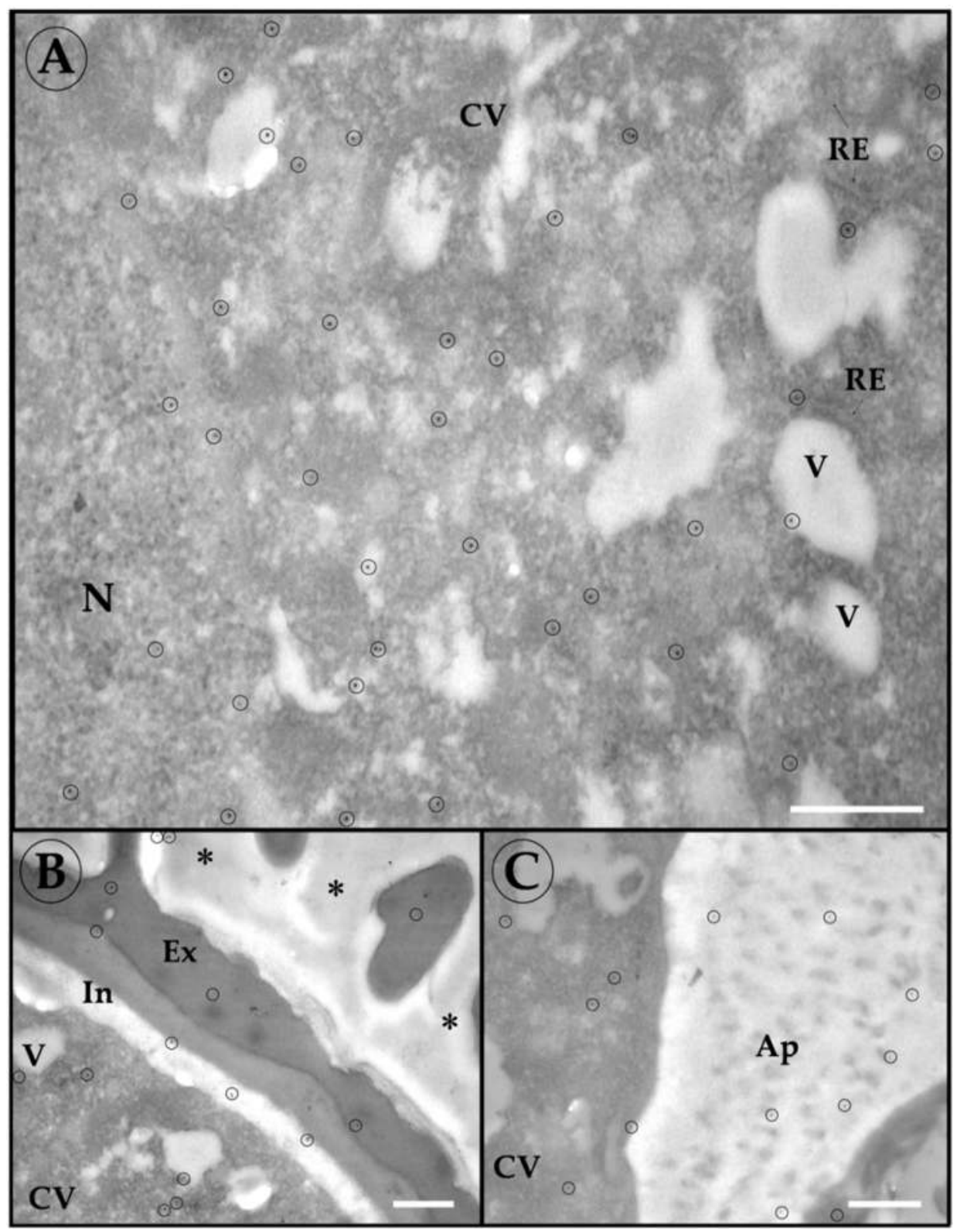

Figure 12. TEM immune-localization of olive pollen profilin in sections of mature pollen (cv Picual) during in vitro germination by using anti-ZmPRO5 antiserum. A) General view of the vegetative cell cytoplasm, B) pollen grain walls, and C) apertural region. The location of the gold particles is highlighted with circles and arrows. Ap: apertures; CV: vegetative cell cytoplasm, Ex: exine, In: intine, M: mitochondria, N: nucleus, P: plastid, ER: endoplasmic reticulum; V: vesicle, asterisks: pollen coat. The bars represent $1 \mu \mathrm{m}$. 


\section{Discussion}

\subsection{Molecular characteristics of profilin explain the pan-allergen character and their specific cross-immune reactivity}

Profilins as pan-allergens are present in a wide variety of plant sources, and responsible for numerous cross-reactions. On the other hand, profilins are also able to elicit allergic responses highly specific by recognition of specific epitopes (immuno-dominant regions of recognition and interaction with $B$ cells and $T$ of the human immune system). IgE antibody production by B lymphocytes IgE-mediated response plays a major role in cross-reactivity between allergens and the symptoms of allergy (Aalberse et al. 1992). However, in addition to humoral responses, has been shown that the cross-reactivity also attends through humoral responses mediated by $\mathrm{T}$ cells, i.e. reactivity to allergens of plant foods (Mal d 1, Api g 1 and Dau c 1) with the pollen allergen Bet v 1. In the first case, it is likely that both fresh and cooked food (in which conformational epitopes are lost), induce $\mathrm{T}$ cell activation and symptoms mediated by them, and do so in the absence of binding to IgE (Bohle et al. 2003). The allergenic responses (mechanisms) should be considered of special relevance, since knowledge gained on antigens recognized by T- and B-cells will allow a better understanding of specific immune responses with applications in allergy therapy (LópezTorrejón et al. 2007).

The "double allergenic activity" of profilin can be explained by the combination of a high structural conservation, together with the presence of a high sequence polymorphism.

The experimental results clearly demonstrate that different forms of profilins have described differential immunological characteristics as they respond differently to the antibodies used. This suggests that the recognition of profilins by the human immune system would also very likely to be differential. Several reasons can justify the broad cross-reactivity of the different profilins:

1. The presence of a number of specific and common surface features in the structure of the majority of allergens can make differences in immune-reactivity among allergens. Typically, a high hydrophobicity of amino acids integrating epitopes, in addition to good accessibility to the region of the protein seems to be key parameters for high reactivity,

2. The epitopes more relevant in determining the reactivity of the profilins are conformational epitopes, not linear. Thus special consideration should be given to the potential electrostatic and solvent exposure of these molecules in order to find out what the specific IgE epitopes responsible for cross-reactions.

3. Secondary structural elements of the proteins such as regions rich in $\alpha$-helices, $\beta$ sheets or turns are factors promoting that reactivity. These characteristics have been observed not only in profilin, but also in other families such as LTP and allergenic storage proteins of seeds (Seong \& Matzinger 2004). Moreover, the similarities between the structure of human and grasses profilins in addition to other different plant species 
might be a cause of the possible role of human profilin in the extension of allergic symptoms caused by profilins of other species in atopic patients (Valenta et al. 1991).

4. Another relevant factor described as a possible cause of cross-reactions in multiple species, even if they are phylogenetically distant, is the presence of polymeric forms of allergens, i. e. plant and human profilin (Valenta et al. 1994). Vrtala et al. (1996) have shown that birch profilin induced an IgG response, subclass 2 (IgG2) in mice and primates, which is typical of polymeric antigens. Maize profilin isoform ZmPRO1 can be in multimeric forms that persist even after denaturing and reducing agents in similar manner that happens with the native human profilin (Babich et al. 1996). In addition, the formation of profilin multimers is not incompatible with the profilin function/activity carried out through interaction with its ligands (Jonckheere et al. 1999). Differential recognition of plant profilin multimers by the immune system is not based in a simple additive effect, because profilin multimers act synergistically to facilitate sterical access to binding sites which present unique epitopes (Psaradellis et al. 2000).

5. Cross-reactivity and pan-allergen character is not the only important feature that distinguishes profilins in their immune-reactivity. Several studies have documented very specific allergenic reactivity of the profilins. Some of these have shown that specific IgE epitopes can even distinguish variables plant profilins, even from the same family, and the reactivity among plant profilins is only partial (Vallverdu et al. 1998). These differences in reactivity can be attributed to the presence of a high polymorphism in these molecules (Radauer et al. 2006).

Polymorphism is a common feature in many allergenic proteins. It has been reported different degrees of polymorphism in diverse allergen sources, which include dust mites (Piboonpocanun et al. 2006), food (Hales et al. 2004, Gao et al. 2005) and pollen allergens of different tree species and herbaceous (Chang et al. 1999). However, although the polymorphism is beginning to be detailed in depth, relatively little is known about the causes which originate. In some cases, the allergen polymorphism has been attributed to the presence of multigene families (Bond et al. 1991). In other allergens, the presence of multiple forms of the allergen can be explained by the existence of posttranslational modifications (Batanero et al. 1996a). In apple (Malus domestica), have been characterized up to 18 genes of Mal d 1, and there is differences in allergenicity depending on the cultivar (Gao et al. 2005) which may be due to this extensive allelic diversity. In olive, it has been shown that polymorphism of the allergen Ole e 1 is clearly linked to genetic background (cultivar) (Hamman-Khalifa et al. 2008), similarly to what happens to Ole e 2, where there are differential molecular characteristics due to polymorphism, which would be sufficient to explain the differences in reactivity allergenic / immunogenic among profilins from different species, different olive varieties, and even among the same isoforms of profilins (JimenezLopez 2008; Jimenez-Lopez et al. 2012).

The experimental data suggest that the profilin family of proteins likely contains numerous functionally-distinctive isoforms, also reflected in differential cellular 
localizations as a result of a differential expression of some forms of profilins in vitro germination of pollen grain, and the preferential localization of some forms of profilins in different cellular compartments. These data also revealed that the differential immunereactivity of profilins is likely the result of the presence of both common and specific epitopes features, which would be generated by the described sequence polymorphism, and might explain differential sensitizations of allergenic patients to olive pollen cultivars as well as cross-reactions between pollens from different species, as well as pollen and food allergens.

In the present work, it has been identified up to five immune-reactive bands to antibodies in the different extracts analyzed, after separation of the polypeptides by electrophoresis. The number of bands identified in other studies (Alché et al. 2007) also ranges from 3 to 5, depending on the separation methods employed, and the observed molecular weight ranges are very similar.

It is noteworthy to see that there is differential reactivity of the profilins in different species (and varieties in the case of the olive tree) to the antibodies used in immunoblot experiments. These differences vary not only depending on the antibody used, but for a given antibody can be observed dramatic differences in the reactivity of a species (varieties), and even between different forms of profilins (different bands) within the same species or variety. These differences have proved to be statistically. These type of experiential evidences can highlight two important aspects that distinguish the immunological reactivity of profilins: i) profilins are responsible for cross-allergenicity between allergens (recognizable bands in almost all species and/or varieties) and ii) other antibodies are able to recognize subtle differences in the structure between different forms of these molecules (differences in the reactivity of protein bands between species and varieties with different antibodies). In this sense, the observed differences in the reactivity of the extracts of different varieties of olive, seems to support the varietal character as discriminatory parameter in pollen allergens, as clearly was demonstrated for other allergens such as Ole e 1 (Hamman-Khalifa et al. 2008), and Ole e 2 (Jimenez-Lopez 2008; Jimenez-Lopez et al. 2012) in the case of olive.

The cellular localization observed for profilins in this work corresponds essentially to that predicted by bioinformatics tools, which is otherwise very similar to that described by other authors. With a few exceptions (eg Fischer et al. 1996 that Phl p 4 located in amyloplasts of pollen from Phleum pratense), most authors reported the profilins localization in the cytoplasm and exine of pollen grain and in the cytoplasm of pollen tube. The olive pollen, profilins are found distributed in the cytoplasm of the pollen grain and pollen tube, without preferential localization or binding to organelles, structures or compartments. The large presence of labeling was also associated to the exine, the material adhered to the exine and the apertural region can be considered distinctive, suggesting evidences of a massive release of the allergen to the media when pollen is hydrated, which has been previously described for Ole e 2 and Ole and 1 (Alché et al. 2004; Morales et al. 2008). 
Immunolocalization experiments using anti-ZmPRO4 and anti-ZmPRO5 confirm the predictions of nuclear localization for olive pollen profilins. Such accumulation may be the result of passive diffusion due to the small size of profilin that allows them to pass through the nuclear pore complex (Yoneda 1997). However, a possible active and selective process by a non-classical signal of nuclear localization, or perhaps other elements such as importin-like proteins might be implicated in that nuclear localization (Yoneda 1997). In animal cells, has been found exportin-like proteins that are specific for profilin (exportin 6) and recognizes only the actin-profilin complex, which export the complex outside the nucleus.

Furthermore, in the nucleus has been also located several natural ligands of profilin like PIP2 (Mazzotti et al. 1995), actin and other ABPs such as ADF-cofilin in maize (Jiang et al. 1997) and CAPG (Lu \& Pollard 2001). Nuclear distribution suggests that profilin could play an important role in controlling the function of nuclear actin (Rando et al. 2000), in addition to be involved in processes such as chromatin condensation and translation signals from cytoplasm to nucleus (Valster et al. 2003).

\subsection{Implications of polymorphism in the diagnosis and allergy therapy}

Cross-reactivity between profilins has broad implications in the phenomena of allergy, being responsible for many cases of double sensitization to pollens and various foods (van Ree 2004). Furthermore, the high cross-reactivity might justify the current use of a single profilin (recombinant profilin of birch pollen, Bet $\mathrm{v} 2$ ) for the diagnosis of allergy.

The existence of high polymorphism and differential reactivity to different profilin isoforms may have a number of consequences for the diagnosis and allergy therapy. Given the differential reactivity of patients to different forms of profilins, it is extremely important that the extracts used in clinical trials should take in consideration the existence of polymorphism in these molecules. As reviewed by Alché et al. (2007), the content of allergens in the protein extracts should be as similar as possible to the panel of proteins to which the atopic patient is usually exposed and reactive. Therefore, in the case of patients with allergy to profilins, it should be carefully analyzed their reactivity to the different isoforms, in order to adjust or "personalize" the treatment. In addition, a great advantage of this customization is the increased safety of immunotherapy treatments, avoiding undesirable sensitization induced "de novo" by immunotherapy, which have been documented by several authors.

New concepts in diagnosis and therapy often include the use of recombinant allergen molecules (Crameri and Rhyner 2006). Recombinant allergens undoubtedly provide tremendous advantages over the use of specific conventional allergen immunotherapy, based on the use of extracts from natural sources. However, a reduction in the number of allergen proteins in the extracts for immunotherapy (as is happening through the exclusive use of a single recombinant profilin form) may lead to the emergence of substantial differences between vaccines and the actual exposure of patients to their environments, 
unless a careful selection of the panel of recombinant allergens for immunotherapy is made. This strategy can be incorporated into virtually all new vaccines currently under development to improve the diagnosis and therapy, and to include the hybrid or modified molecules, allergen fragments, multimers, or the design of hypoallergenic proteins. For instance, a detailed reactivity analysis of isoforms present in particular cultivars, combined with protein sequence analysis, could aid the design of hypoallergenic proteins, which might complement the strategies currently in use (Marazuela et al. 2007). Besides a thorough investigation of the allergenic isoforms of the germplasm species could also help identifying natural hypoallergenic profilin isoforms in some cultivars of olive.

\section{Conclusion}

This study highlights and support a previous work developed by the same group (JimenezLopez 2008; Jimenez-Lopez et al. 2012) about multi-functionality and regulatory importance evolved from sequence polymorphism of pollen profilins, as a potential mechanism to generate multiple profilin isovariants in a wide genetic (germplasm) background of particular plant species like olive.

This polymorphism in profilin isovariants is reflected in the differential immune-reactivity exhibited by different cultivars to antibodies generated against vegetative and reproductive profilins, in addition to differential subcellular location in pollen grains and germinated pollen tubes. Both characteristics lead to strongly propose that functional differences among profilin isoforms, as well as regulatory pathways throughout profilin-ligand binding properties, could have a direct influence in the subcellular location and actin cytosqueleton dynamics as direct consequence of polymorphism. Furthermore, this variability reflected in the epitopes generation in panallergen like Ole e 2, has extreme importance in the standardization of formulations for allergy diagnosis in clinical trials and tailoredimmunotherapy development.

\section{Author details}

Jose C. Jimenez-Lopez, Sonia Morales, Juan D. Alché and María I. Rodriguez-Garcia Department of Biochemistry, Cell and Molecular Biology of Plants, Estación Experimental del Zaidin, Spanish National Research Council (CSIC), Granada, Spain

Dieter Volkmann

Institute of Cellular and Molecular Botany (IZMB), Department of Plant Cell Biology, University of Bonn, Germany

\section{Acknowledgement}

This study was supported by the following European Regional Development Fund cofinanced grants: MCINN BFU 2004-00601/BFI, BFU 2008-00629, BFU2011-22779, CICE (Junta 
de Andalucía) P2010-CVI15767, P2010-AGR6274, P2011-CVI-7487, P2011-CVI-7487, and by the coordinated project Spain/Germany MEC HA2004-0094.

The funders had no role in the study, design or decision to publish.

\section{References}

Alché, J.D., Castro, A.J., Jimenez-Lopez, J.C., Morales, S., Zafra, A., Hamman-Khalifa, A.M., and Rodríguez-García M.I. (2007). Differential characteristics of olive pollen from different cultivars: biological and clinical implications. Journal investigational allergology and clinnical immunology, Vol. 17, Suppl. 1, pp. 17-23.

Alché, J.D., M'rani-Alaoui, M., Castro, A.J., \& Rodríguez-García, M.I. (2004). Ole e 1, the major allergen from olive (Olea europaea L.) pollen increases its expression and is released to the culture medium during in vitro germination. Plant and cell physiology, Vol. 45, No. 9, pp. 1149-1157.

Alché, J.D., Jimenez-Lopez, J.C., Wei, W., Castro-Lopez, A.J., and Rodríguez-García, M.I. (2006). Biochemical characterization and cellular localization of $11 S$ type storage proteins in olive (Olea europaea L.) seeds. Journal of Agricultural and Food Chemistry, Vol. 54 , pp. 5562-5570.

Aalberse, R.B. (1992). Clinically significant cross-reactivities among allergens. International archives of allergy and immunology, Vol. 99, pp. 261-264.

Babich, M., Foti, L.R.P., Sykaluk, L.L., and Clark, C.R. (1996). Profilin Forms Tetramers That Bind to G-Actin. Biochemical and Biophysical Research Communications, Vol. 218, No. 1, pp. 125-131.

Baluška, F., Jasik, J., Edelmann, H.G., Salajová, T. and Volkmann, D. (2001). Latrunculin Binduced plant dwarfism: Plant cell elongation is F-actin-dependent. Developmental biology, Vol. 231, pp. 113-124.

Baluška, F., and Volkmann, D. (2002) Actin-driven polar growth of plant cells. Trends in Cell Biology, Vol. 12, N. 1, pp. 14

Batanero, E., Villalba, M., Monsalve, R.I., and Rodríguez, R. (1996a). Cross-reactivity between the major allergen from olive pollen and unrelated glycoproteins: Evidence of an epitope in the glycan moiety of the allergen. Journal of allergy and clinnical immunology, Vol. 97, pp. 1264-1271.

Bohle, B., Radakovics, A., Jahn-Schmid, B., Hoffmann-Sommergruber, K., Fischer, G.F., and Ebner, C. (2003). Bet v 1, the major birch pollen allergen, initiates sensitization to Api g 1 , the major allergen in celery: evidence at the $\mathrm{T}$ cell level. European Journal of Immunology, Vol. 33, N. 12, pp. $3303-3310$.

Bond, J.F., Garman, R.D., Keating, K.M., Briner, T.J., Rafnar, T., Klapper, D.G., and Rogers, B.L. (1991). Multiple Amb a I allergens demonstrate specific reactivity with IgE and T cells from ragweed-allergic patients. Journal of Immunology, Vol. 146, pp. 3380-3385. 
Braun, M., Baluska, F., von Witsch, M., and Menzel, D. (1999). Redistribution of actin, profilin and phosphatidylinositol-4, 5-bisphosphate in growing and maturing root hairs. Planta, Vol. 209, pp. 435-443.

Buss, F., Temm-Grove, C., Henning, S., and Jockusch, B.M. (1992). Distribution of profilin in fibroblasts correlates with the presence of highly dynamic actin filaments. Cell motility and the cytoskeleton, Vol. 22, N. 1, pp. 51-61.

Chang, Z.N., Peng, H.J., Lee, W.C., Chen, T.S., Chua, K.Y., Tsai, L.C., Chi, C.W., and Han, S.H. (1999). Sequence polymorphism of the group 1 allergen of Bermuda grass pollen. Clinnical and experimental allergy, Vol. 29, pp. 488-496.

Crameri, R., and Rhyner, C. (2006). Novel vaccines and adjuvants for allergen-specific immunotherapy. Current opinion in immunology, Vol. 18, N. 6, pp. 761-768.

Deeks, M.J., Hussey, P.J., and Davies, B. (2002). Formins: intermediates in signaltransduction cascades that affect cytoskeletal reorganization. Trends in Plant Science, Vol. 7, pp. 13601385.

Fedorov, A.A., Ball, T., Valenta, R., and Almo, S.C. (1997). X-ray crystal structures of birch pollen profilin and Phl p 2. International archives of allergy immunology, Vol. 113, N. 1-3, pp. 109-113.

Fischer, S., Grote, M., Fahlbusch, B., Müller, W.D., Kraft, D., and Valenta, R. (1996). Characterization of $\mathrm{Phl} \mathrm{p} \mathrm{4,} \mathrm{a} \mathrm{major} \mathrm{timothy} \mathrm{grass} \mathrm{(Phleum} \mathrm{pratense)} \mathrm{pollen} \mathrm{allergen.} \mathrm{The}$ Journal of allergy and clinnical immunology, Vol. 98, N. 1, pp. 189-198.

Gao, Z.S., Weg, W.E., Schaart, J.G., Arkel, G., Breiteneder, H., Hoffmann-Sommergruber, K., \& Gilissen, L.J. (2005). Genomic characterization and linkage mapping of the apple allergen genes Mal d 2 (thaumatin-like protein) and Mal d 4 (profilin). Theoretical and applied genetics, Vol. 111, N. 6, pp. 1087-1097.

Games, P.A., and Howell, J.F. (1976). Pairwise multiple comparison procedures with unequal n's and/or variances: A Monte Carlo study. Journal of Educational Statistics, Vol. $1, \mathrm{~N}^{\circ} .2$, pp. 113-125.

Gibbon, B.C., Zonia, L.E., Kovar, D.R., Hussey, P.J., \& Staiger, C.J. (1998). Pollen profilin function depends on interaction with proline-rich motifs. Plant Cell, Vol. 10, pp. 981-994; [Correction: Plant Cell, Vol. 11, pp. 1603]

Grote, M., Swoboda, I., Meagher, R.B., and Valenta, R. (1995). Localization of profilin and actin-like immune-reactivity in vitro-germinated tobacco pollen tubes by electron microscopy after special water-free fixation techniques. Sexual Plant Reproduction, Vol. 8, pp. 180-186.

Grote, M., Vrtala, S., and Valenta, R. (1993). Monitoring of two allergens, Bet v I and profilin, in dry and rehydrated birch pollen by immunogold electron microscopy and immunoblotting. The journal of histochemistry and Cytochemistry, Vol. 41, N. 5, pp. 745750.

Hales, B.J., Bosco, A., Mills, K.L., Hazell, L.A., Loh, R., Holt, P.G., and Thomas, W.R. (2004). Isoforms of the major peanut allergen Ara $\mathrm{h}$ 2: $\operatorname{IgE}$ binding in children with peanut allergy. International archives of allergy and immunology, Vol. 135, pp. 101-107. 
Hamman Khalifa, A., Castro, A.J., Jimenez-Lopez, J.C., Rodríguez García, M.I., and Alché, J.D. (2008). Olive cultivar origin is a major cause of polymorphism for Ole e 1 pollen allergen. BMC Plant Biology, Vol. 8, pp. 10

Hess, M.W., and Valenta, R. (1997). Profilin revealed in pollen nuclei: immuno-electron microscopy of high-pressure frozen Ledebouria socialis Roth (Hyacinthaceae). Sexual Plant Reproduction, Vol. 10, pp. 283-287.

Hess, M.W., Mittermann, I., Luschnig, C., and Valenta, R. (1995). Immunocytochemical localisation of actin and profilin in the generative cell of angiosperm pollen: TEM studies on high-pressure frozen and freeze-substituted Ledebouria socialis Roth (Hyacinthaceae). Histochemistry and Cell Biology, Vol. 104, N. 6, pp. 443-451.

Holzinger, A., Valenta, R., and Lütz-Meindl, U. (2000). Profilin is localized in the nucleusassociated microtubule and actin system and is evenly distributed in the cytoplasm of the green alga Micrasterias denticulata. Protoplasma, Vol. 212, pp. 197-205.

Huang, S.R., McDowell, J.M., and Weise, M.J., and Meagher, R.B. (1996). The Arabidopsis profilin gene family. Evidence for an ancient split between constitutive and pollenspecific profilin genes. Plant Physiology, Vol. 111, pp. 115-126.

Janssen, K.P., and Schleicher, M. (2001). Dictyostelium discoideum: a genetic model system for the study of professional phagocytes. Profilin, phosphoinositides and the lmp gene family in Dictyostelium. Biochimica et biophysica acta, Vol. 1525, N. 3, pp. 228-233.

Jiang, C.J., Weeds, A.G., and Hussey, P.J. (1997). The maize actin-depolymerizing factor, $\mathrm{ZmADF}$, redistributes to the growing tip of elongating root hairs and can be induced to translocate into the nucleus with actin. Plant Journal, Vol. 12, pp. 1035-1043.

Jimenez-Lopez, J.C. PhD Thesis 2008. Molecular characterization of profilin polymorphism in the pollen of olive and other allergogenic species. ISBN: 978-84-691-4573-9; DOI: $10481 / 1871$

Jimenez-Lopez, J.C., Morales, S., Castro, A.J., Volkmann, D., Rodríguez-García, M.I., and Alché, J.D. (2012). Characterization of profilin polymorphism in pollen with a focus on multifunctionality. PLoS One, Vol. 7, No. 2, pp. e30878.

Jonckheere, V., Lambrechts, A., Vandekerckhove, J., and Ampe, C. (1999). Dimerization of profilin II upon binding the (GP5)3 peptide from VASP overcomes the inhibition of actin nucleation by profilin II and thymosin beta4. FEBS Letter, Vol. 447, pp. 257263.

Jockusch, B.M., Murk, K., and Rothkegel, M. (2007). The profile of profilins. Reviews of physiology, biochemistry and pharmacology, Vol. 159, pp. 131-149.

Kovar, D.R., Drøbak, B.K., Collings, D.A., and Staiger, C.J. (2001). The characterization of ligand specific maize (Zea mays) profilin mutants. Biochemical Journal, Vol. 358, pp. 4957.

Kovar, D.R., Drøbak, B.K., and Staiger, C.J. (2000). Maize profilin isoforms are functionally distinct. Plant Cell, Vol. 12, pp. 583-598. 
Kandasamy, M.K., McKinney, E.C., and Meagher, R.B. (2002). Plant profilin isovariants are distinctly regulated in vegetative and reproductive tissues. Cell motility and the cytoskeleton, Vol. 52, N. 1, pp. 22-32.

Karakesisoglou, I., Schleicher, M., Gibbon, B.C., and Staiger, C.J. (1996). Plant profilins rescue the aberrant phenotype of profilin-deficient Dictyostelium cells. Cell motility and the cytoskeleton, Vol. 34, N. 1, pp. 36-47.

Levene, H. (1960). Robust tests for equality of variances. In: Ingram Olkin, Harold Hotelling, et al. (Ed.). Stanford University Press, pp 278-292.

López-Torrejón, G., Díaz-Perales, A., Rodríguez, J., Sánchez-Monge, R., Crespo, J.F., Salcedo, G., and Pacios, L.F. (2007). An experimental and modeling-based approach to locate IgE epitopes of plant profilin allergens. Journal of Allergy and Clinnical Immunology, Vol. 119, $\mathrm{N}^{\circ}$. 6, pp. 1481-1488.

Lu, J., and Pollard, T.D. (2001). Profilin binding to poly-L-proline and actin monomers along with ability to catalyze actin nucleotide exchange is required for viability of fission yeast. Molecular and Cellular Biology, Vol. 12, pp. 1161-1175.

Marazuela, E.G., Rodríguez, R., Barber, D., Villalba, M., and Batanero, E. (2007). Hypoallergenic mutants of Ole e 1, the major olive pollen allergen, as candidates for allergy vaccines. Clinnical and experimental allergy, Vol. 37, N. 2, pp. 251-60.

Mazzotti, G., Zini, N., Rizzi, E., Rizzoli, R., Galanzi, A., Ognibene, A., Santi, S., Matteucci, A., Martelli, A.M., and Maraldi, N.M. (1995). Immunocytochemical detection of phosphatidylinositol 4,5-biphosphate localization sites within the nucleus. Journal of Histochemistry and Cytochemistry, Vol. 43, pp. 181-191.

McDowell, J.M., Huang, S., McKinney, E.C., An, Y.Q., and Meagher, R.B. (1996), Structure and evolution of the actin gene family in Arabidopsis thaliana. Genetics, Vol. 142, pp. 587602.

Mehta, C.R., and Patel, N.R. (1983). A network algorithm for performing Fisher's exact test in contingency tables. Journal of American Statistical Association, Vol. 78, N. 382, pp. 427434.

Morales, S., Jimenez-Lopez, J.C., Castro, A.J., Rodríguez-García, M.I., and Alché, J.D. (2008). Olive pollen profilin (Ole e 2 allergen) co-localizes with highly active areas of the actin cytoskeleton and is released to the culture medium during in vitro pollen germination. Journal of Microscopy-Oxford, Vol. 231, No. 2, pp. 332-341.

Neidt, E.M., Scott, B.J., and Kovar, D.R. (2009). Formin differentially utilizes profilin isoforms to rapidly assemble actin filaments. Journal of Biological Chemistry, Vol. 284, pp. 673-684.

Piboonpocanun, S., Malainual, N., Jirapongsananuruk, O., Vichyanond, P., and Thomas, W.R. (2006). Genetic polymorphisms of major house dust mite allergens. Clinnical and experimental allergy, Vol. 36, pp. 510-516.

Psaradellis, T., Kao, N.L, and Babich, M. (2000). Recombinant Zea mays profilin forms multimers with pan-allergenic potential. Allergology International, Vol. 49, pp. 27-35. 
Radauer, C., Willerroider, M., Fuchs, H., Hoffmann-Sommergruber, K., Thalhamer, J., Ferreira, F., and Scheiner, O. \& Breiteneder H. (2006). Cross-reactive and speciesspecific immunoglobulin E epitopes of plant profilins: an experimental and structurebased analysis. Clinnical and experimental allergy, Vol. 36, N. 7, pp. 920-929.

Rando, O.J., Zhao, K., and Crabtree, G.R. (2000). Searching for a function for nuclear actin. Trends in Cell Biology, Vol. 10, pp. 92-97.

Schmidt von Braun, S., and Schleiff, E. (2008). The chloroplast outer membrane protein Chup1 interacts with actin and profilin. Planta, Vol. 227, N. 5, pp. 1151-1159.

Seong, S.Y., and Matzinger, P. (2004). Hydrophobicity: an ancient damage-associated molecular pattern that initiates innate immune responses. Nature Immunology, Vol. 4, $\mathrm{N}^{\circ} .6$, pp. 469-478.

Shapiro, S.S., and Wilk, M.B. (1965). An analysis of variance for normality (complete samples). Biometrika, Vol. 52, pp. 591-611.

Thorn, K.S., Christensen, H.E., Shigeta, R., Huddler, D., Lindberg, U., Chua, N.H., and Schutt, C.E. (1997). The crystal structure of a major allergen from plants. Structure, Vol. 5, pp. 19-32.

Valenta, R., Ball, T., Vrtala, S., Duchêne, M., Kraft, D., and Scheiner, O. (1994). cDNA cloning and expression of timothy grass (Phleum pratense) pollen profilin in Escherichia coli: comparison with birch pollen profilin. Biochemical and biophysical research communications, Vol. 199, N. 1, pp. 106-118.

Valenta, R., Duchêne, M., Pettenburger, K., Sillaber, C., Valent, P., Bettelheim, P., Breitenbach, M., and Rumpold, H., Kraft, D., and Scheiner, O. (1991). Identification of profilin as a novel pollen allergen; IgE autoreactivity in sensitized individuals. Science, Vol. 253, pp. 557-560.

Vallverdu, A., Asturias, J.A., Arilla, M.C., Gomez-Bayon, N., Martinez, A., and Martinez, J., and Palacios R. (1998). Characterization of recombinant Mercurialis annua major allergen Mer a 1 (profilin). Journal of Allergy and Clinnical Immunology, Vol. 101, N. 3, pp. 363-370.

Valster, A.H., Vidali, L., and Hepler, P.K. (2003). Nuclear localization of profilin during the cell cycle in Tradescantia virginiana stamen hair cells. Protoplasma, Vol. 222, pp. 85-95.

van Ree, R. (2004). Clinical importance of cross-reactivity in food allergy. Current Opinion in Allergy and Clinnical Immunology, Vol. 4, N. 3, pp. 235-240.

Vidali, L., and Hepler, P.K. (1997). Characterization and localization of profilin in pollen grains and tubes of Lilium longiflorum. Cell motility and the cytoskeleton, Vol. 36, $\mathrm{N}^{\circ} .4$, pp. 323-338.

Vidali, L., Pérez, H.E., Valdés López, V., Noguez, R., Zamudio, F., and Sánchez, F. (1995). Purification, characterization, and cDNA cloning of profilin from Phaseolus vulgaris. Plant physiology, Vol. 108, N. 1, pp. 115-123.

von Witsch, M., Baluška, F., Staiger, C.J., and Volkmann, D. (1998). Profilin is associated with the plasma membrane in microspores and pollen. European Journal of Cell Biology, Vol. 77, N. 4, pp. 303-312. 
Yoneda, Y. (1997). How proteins are transported from cytoplasm to the nucleus. Journal of Biochemistry, Vol. 121, pp. 811-817. 